Nat. Hazards Earth Syst. Sci., 17, 2181-2198, 2017

https://doi.org/10.5194/nhess-17-2181-2017

(C) Author(s) 2017. This work is distributed under

the Creative Commons Attribution 3.0 License.

\title{
Landslide displacement prediction using the GA-LSSVM model and time series analysis: a case study of Three Gorges Reservoir, China
}

\author{
Tao Wen ${ }^{1}$, Huiming Tang ${ }^{1,2}$, Yankun Wang ${ }^{1,2}$, Chengyuan Lin ${ }^{1}$, and Chengren Xiong ${ }^{2}$ \\ ${ }^{1}$ Faculty of Engineering, China University of Geosciences, Wuhan 430074, Hubei, People's Republic of China \\ ${ }^{2}$ Three Gorges Research Center for Geohazards of Ministry of Education, China University of Geosciences, Wuhan 430074, \\ Hubei, People's Republic of China
}

Correspondence to: Huiming Tang (tanghm@cug.edu.cn)

Received: 28 February 2017 - Discussion started: 29 March 2017

Revised: 28 October 2017 - Accepted: 2 November 2017 - Published: 7 December 2017

\begin{abstract}
Predicting landslide displacement is challenging, but accurate predictions can prevent casualties and economic losses. Many factors can affect the deformation of a landslide, including the geological conditions, rainfall and reservoir water level. Time series analysis was used to decompose the cumulative displacement of landslide into a trend component and a periodic component. Then the least-squares support vector machine (LSSVM) model and genetic algorithm (GA) were used to predict landslide displacement, and we selected a representative landslide with episodic movement deformation as a case study. The trend component displacement, which is associated with the geological conditions, was predicted using a polynomial function, and the periodic component displacement which is associated with external environmental factors, was predicted using the GALSSVM model. Furthermore, based on a comparison of the results of the GA-LSSVM model and those of other models, the GA-LSSVM model was superior to other models in predicting landslide displacement, with the smallest root mean square error (RMSE) of $62.4146 \mathrm{~mm}$, mean absolute error (MAE) of $53.0048 \mathrm{~mm}$ and mean absolute percentage error (MAPE) of $1.492 \%$ at monitoring station ZG85, while these three values are $87.7215 \mathrm{~mm}, 74.0601 \mathrm{~mm}$ and $1.703 \%$ at ZG86 and $49.0485 \mathrm{~mm}, 48.5392 \mathrm{~mm}$ and $3.131 \%$ at ZG87. The results of the case study suggest that the model can provide good consistency between measured displacement and predicted displacement, and periodic displacement exhibited good agreement with trends in the major influencing factors.
\end{abstract}

\section{Introduction}

In the Three Gorges Reservoir region, landslides are the main type of geohazard, and they cause critical harm to individuals and property each year (Du et al., 2013; Yao et al., 2013; Lian et al., 2014; Cao et al., 2016). The displacement prediction of landslides is a major focus in the field of landslide research (Sassa et al., 2009; Du et al., 2013). Comprehensive analyses of landslide response and displacement predictions of landslide based on external factors are effective methods that rely on landslide deformation data. The evolution process of landslide is a complex nonlinear process caused by the complex interaction of different factors. The accurate prediction of reservoir landslide processes is an important basis for early prevention, and it can reduce the loss of property and lives (Corominas et al., 2005). Therefore, geological surveying, monitoring, landslide prevention and landslide prediction must be improved to minimize the losses caused by landslides (Kirschbaum et al., 2010; Miyagi et al., 2011; Ahmed, 2013). A landslide can be regarded as a nonlinear and dynamic system that is affected by external factors, such as rainfall, reservoir water levels and groundwater. (Guzzetti et al., 2005; Kawabata and Bandibas, 2009). Due to the influences of external factors, deformation displacement of landslide generally exhibits the same tendencies as the variations in external factors, which can result in misleading landslide prediction. Displacement time series is usually considered as a direct representation of complex nonlinear dynamical behavior of landslide.

In recent years, grey system models, time series models, neural network models, extreme learning machines, support vector machines (SVM), etc. have been widely used 
for landslide displacement prediction (Wang, 2003; Pradhan et al., 2014; Gelisli et al., 2015; Goetz et al., 2015; Kavzoglu et al., 2015). Previously, landslide susceptibility maps were assessed using a back propagation (BP) artificial neural network and logistic regression analysis (Nefeslioglu et al., 2008). Additionally, dynamic time series predictors were proposed based on echo state networks (Yao et al., 2013). Lian et al. (2013) used an extreme learning machine and ensemble empirical mode decomposition to predict landslide displacement. Although these models were constructed based on different algorithms, each has strengths and weaknesses. Grey system models are widely used in analyses of exponential time series. However, for complex nonlinear slope displacement series, prediction results can yield considerable error (Yin and Yu, 2007; Sun et al., 2008). Additionally, autocorrelation coefficients, partial correlation coefficients and pattern recognition features are difficult to determine via time series analysis (Brockwell and Davis, 2013; Turner et al., 2015). The neural network method is a powerful tool in landslide prediction (Liu et al., 2014; Lian et al., 2015). However, the conventional neural network has many limitations, including overfitting and a shortage of theoretical guidance in the selection of the number of network nodes in the hidden layer, which diminishes its prediction ability (Hwang et al., 2014). In addition, the neural network neglects practical issues by using a predefined activation function. Compared with traditional learning algorithms, although extreme learning machines are characterized by high generalization, good performance and fast computing speed, their output is different at different times due to the use of randomly selected input (Lian et al., 2014). Thus, it is difficult to reflect large quantities of information completely and predict landslide displacement accurately using these models because landslide displacement is actually a finite time series.

The SVM model can effectively overcome the limitations of other methods, including small sample sizes, high dimensionality and nonlinearity. Many studies have illustrated the ability of SVM models to recognize learning patterns, such as nonlinear regression, and obtain the global optimum solutions to these problems (Feng et al., 2004; Marjanović et al., 2011; Micheletti et al., 2011; Hong et al., 2016). Although these problems can be transformed into quadratic convex programming problems, the computation speed of the SVM model is slow when the training data set is large or the dimensionality is high (Zhang et al., 2009). To overcome these inadequacies, we use the least-squares support vector machine (LSSVM) proposed by Suykens and Vandewalle (1999), which is a supervised learning model that has been widely applied in other machine learning problems, such as function fitting. The LSSVM model uses the square sum of the least-squares linear system error as the loss function and solves the problem by transforming it into a set of equations, which increases the solution speed and reduces the required calculation resources (Suykens et al., 2002; Lv et al., 2013; Xu and Chen, 2013; Zhang et al., 2013). Additionally, this method yields good performance in pattern recognition and nonlinear function fitting. However, the selection of parameters is crucial to developing an efficient LSSVM model due to its sensitivity to small variations in the parameters.

Currently, several intelligent algorithms are used to solve optimization problem, such as the GA (Li et al., 2010; Ali et al., 2013), grid algorithm (Lin, 2001), particle swarm optimization (Vandenbergh and Engelbercht, 2006) and genetic programming (Garg and Tai, 2011; Shen et al., 2012). However, compared with the GA, the grid algorithm is tedious and cannot yield satisfactory results (Gu et al., 2011). For discrete optimization problems, particle swarm optimization performs poorly and often yields local optima (Fei et al., 2009). In addition, genetic programming, which was developed by Koza (1992), provides solutions to complex problems using evolutionary algorithms, and the method is typically expressed as a tree structure that consists of terminals and functions; however, it is difficult to generate new individuals, which seriously affects the convergence rate (Garg et al., 2014). The genetic algorithm (GA) is a global optimization algorithm that uses highly parallel, random and adaptive searching based on biological natural selection and optimization. Thus, the method is particularly suitable for solving complex and nonlinear problems (Li et al., 2010; Ali et al., 2013; Cai et al., 2016). In this paper, the GA is selected as the method of parameter optimization in the LSSVM due to its advantages in determining the unknown parameters that are consistent between the predicted data and the measured data. By introducing the GA, some key parameters of the LSSVM model can be derived automatically. Therefore, we select the combination of the LSSVM model and the GA to predict landslide displacement.

Due to the influences of rainfall, reservoir water level and human activities on the monitoring data of landslide displacement, most monitoring data series are incomplete or highly variable. These issues introduce uncertainty into the mathematical model and increase the difficulty of prediction. To overcome this and obtain the main error sources, a time series analysis of displacement is conducted by decomposing the monitoring data series into several components ( $\mathrm{Du}$ et al., 2013). Then, the monitoring data series are simulated using the moving average method. The Shuping landslide, a typical landslide with episodic movement deformation, was taken as an example to validate the GA-LSSVM model with time series analysis.

\section{Methodology}

\subsection{Time series analysis of displacement}

Cumulative displacement of landslides is caused by the combined effects of internal geological conditions (lithology, ge- 
ological structure, topography, etc.) and external environmental factors (rainfall, reservoir water level, groundwater, etc.). The displacement of landslide sequence is an instability time series. The landslide displacement caused by the former increases generally with time, which reflects the trend in cumulative displacement. Landslide deformation exhibits longlasting and continuous movements under gravity loads that are affected by the creep characteristic (Desai et al., 1995). One of the important reasons that influence the creep behavior is the expression of the response of geological materials and interfaces. Landslide deformation is often characterized by creep, which generally needs to undergo three stages, initial deformation, stable deformation and accelerated deformation stage. However, the landslide displacement induced by the latter is approximately periodic. Therefore, a landslide displacement sequence is an instability time series with a periodic episodic movement characteristic. According to time series analysis, cumulative displacement can be decomposed into three portions as follows:

$y_{t}=p_{t}+q_{t}+\varepsilon_{t}$,

where $y_{t}$ is the cumulative displacement, $p_{t}$ is the trend component displacement, $q_{t}$ is the periodic component displacement and $\varepsilon_{t}$ is the random component displacement.

However, it is difficult to obtain relevant data regarding the random component (wind loads, car loads, etc.) due to the lack of advanced monitoring methods. In this paper, the random component displacement is not considered. Therefore, we can simplify the time series model as follows.

$y_{t}=p_{t}+q_{t}$

The trend component can be extracted using the moving average method as follows:

$A_{i}=\left\{a_{1}, a_{2}, \cdots, a_{j}, \cdots, a_{n}\right\}$,

$\overline{p_{t}}=\frac{a_{t}+a_{t-1}+\cdots+a_{t-k-1}}{k}(t=k, k+1, \cdots, n)$,

where $A_{i}$ is the time series of cumulative displacement of the $i$ th monitoring system $(i=1,2, \ldots, m), a_{j}$ is the cumulative displacement of the $i$ th monitoring system at time $j(j=1$, $2, \ldots, n), \overline{p_{t}}$ is the extracted value of the trend component and $k$ is the moving average period.

The periodic component displacement can be acquired by subtracting the trend component displacement from the cumulative displacement. Therefore, the time series model not only reflects the relationship between each component of cumulative displacement but also provides mathematical and physical meaning for landslide displacement prediction.

\subsection{LSSVM}

The LSSVM model is a regression prediction method with nonlinear characteristics based on a statistical learning theory, and it is regarded as an improved form of the SVM
(Vapnik, 1995; Abdi and Giveki, 2013). First, after dividing the sample data into training samples and testing samples, the training samples are plotted in a high-dimensional feature space via nonlinear mapping. Then, the optimal decision function model is obtained for the best-fitted results by training the sample data $\left(x_{j}, y_{j}\right)$, where $j=1,2,3, \ldots, n$. The regression function of the LSSVM can be expressed as follows:

$f(x)=\boldsymbol{W}^{T} \varphi(x)+b$,

where $\boldsymbol{W}^{T}$ is the weight vector, $\varphi(x)$ is a nonlinear mapping function that maps the sample data into the feature space, $x$ is the input, $y$ is the output and $b$ is the offset.

By searching a function $f(x)$ that adjusts the dispersion degree of the training samples, we can obtain a riskminimized solution. This solution can be written using the structural risk minimization principle:

Minimize

$\frac{1}{2} \boldsymbol{W}^{T} W+\frac{C}{2} \sum_{j=1}^{n} \xi_{j}^{2}$,

which is subject to

$y_{j}=\boldsymbol{W}^{T} \varphi\left(x_{j}\right)+b+\xi_{j}(j=1,2, \cdots, n)$,

where $C$ is a penalty factor representing the penalty degree of the training samples, $b$ is the offset and $\xi_{j}$ is the relaxation factor.

Based on the Lagrange equation and duality theory, the optimization problem can be converted into a dual problem:

$$
\begin{aligned}
L(W, b, \xi, \alpha) & =\frac{1}{2} \boldsymbol{W}^{T} W+\frac{C}{2} \sum_{j=1}^{n} \xi_{j}^{2}-\sum_{j=1}^{n} \alpha_{j}\left(\boldsymbol{W}^{T} \varphi\left(x_{j}\right)\right. \\
& \left.+b+\xi_{j}-y_{j}\right),
\end{aligned}
$$

where $\alpha_{j}$ is the Lagrange multiplier.

The solution of the optimization equation is obtained by solving the partial differential form of the Lagrange equation with respect to $W, b, \xi_{j}$ and $\alpha_{j}$. The optimization equations are expressed as follows.

$$
\left\{\begin{array}{l}
\frac{\partial L}{\partial W}=0 \Rightarrow W=\sum_{j=1}^{n} \alpha_{j} y_{j} \varphi\left(x_{j}\right) \\
\frac{\partial L}{\partial b}=0 \Rightarrow \sum_{j=1}^{n} \alpha_{j} y_{j}=0 \\
\frac{\partial L}{\partial \xi_{j}}=0 \Rightarrow \alpha_{j}=C \xi_{j} \\
\frac{\partial L}{\partial \alpha_{j}}=0 \Rightarrow y_{j}\left[W^{T} \varphi\left(x_{j}\right)+b\right]-1+\xi_{j}
\end{array}\right.
$$

The linear equations can be obtained by solving Eq. (9) with the elimination of $W$ and $\xi$ :

$$
\left[\begin{array}{ll}
0 & I^{T} \\
I & Z Z^{T}+C^{-1} \mathbf{E}
\end{array}\right]\left[\begin{array}{l}
b \\
\alpha
\end{array}\right]=\left[\begin{array}{l}
0 \\
y
\end{array}\right],
$$


where $\quad y=\left[y_{1}, y_{2}, \cdots, y_{l}\right]^{T}, \quad I=[1, \cdots 1]^{T}, \quad \alpha=$ $\left[\alpha_{1}, \alpha_{2}, \cdots, \alpha_{l}\right]^{T}, \quad Z=\left[\varphi\left(x_{1}\right), \varphi\left(x_{2}\right), \cdots, \varphi\left(x_{l}\right)\right]^{T}$ and $\mathbf{E}$ is the unit matrix with $l$ dimensions.

Then, the regression prediction model of the LSSVM can be rewritten based on the above optimization problem:

$f(x)=\sum_{j=1}^{n} \alpha_{j} K\left(x, x_{j}\right)+b$,

where $K\left(x_{j}, x\right)$ is a kernel function.

In the paper, we select the radial basis kernel function as the kernel function in the LSSVM model to obtain the optimal solutions due to its strong nonlinear mapping ability and wide convergence domain (Min and Lee, 2005; Altınel et al., 2015; Elbisy 2015; Farzan et al., 2015):

$K\left(x_{j}, x\right)=\exp \left(-\left(x-x_{j}\right)^{2}\right) /\left(2 \sigma^{2}\right)$

where $\sigma$ is a parameter of the kernel function.

The equation between $\mathrm{C}$ and $\sigma$ expressed jointly in Eqs. (5)-(10) is extremely complicated, which is inconvenient to be expressed by a certain formula. However, the parameter of the model $C$ and the parameter of the kernel function $\sigma$ significantly influence the prediction performance. The parameter $C$ represents the error tolerance. The more accurate the parameter is, the higher the prediction performance is, but this can lead to overtraining. The parameter $\sigma$ implicitly determines the spatial distribution of data mapping in the new feature space. Therefore, some measures should be taken to optimize the LSSVM parameters.

\subsection{GA}

The GA is a computational model commonly used to simulate natural selection and the biological evolution processes of genetic mechanisms. The GA provides solutions for complicated problems using evolutionary algorithms (Levasseur et al., 2008; Hejazi et al., 2013). The typical genetic operations include selection, crossover and mutation.

Based on certain methods and theories, selection operations, such as the fitness-ratio selection algorithm, ranking algorithm, Monte Carlo selection and tournament selection, are commonly used to choose a parental generation from a population based on an individual's fitness value. Crossover operation can generate two new offspring by selecting random codes from two parents and then exchanging their respective branches. Point mutation is commonly used as the mutation operator. By selecting a random node from a parent, a new individual is generated by substituting the selected random node into another parent branch. A typical GA is shown in Fig. 1. Selection operations, crossover operations and mutation operations are probabilistic, and with a probability of over $90 \%$ crossover operations are the most widely used.

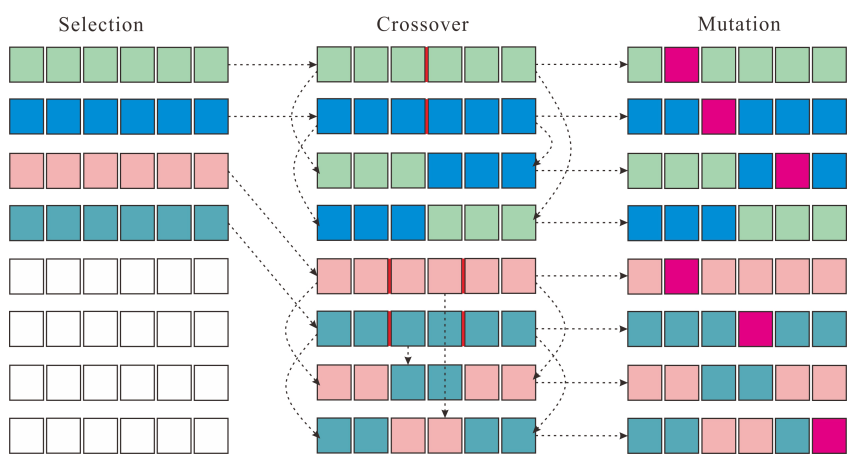

Figure 1. Diagram of genetic operations.

\subsection{GA-LSSVM model}

To obtain the best model, the parameters of the model must be carefully selected in advance (Duan et al., 2003). According to some research results (Lessmann et al., 2005; Pourbasheer et al., 2009), the GA has the advantages of reducing the blindness of artificial selection and enhancing the discrimination ability of the LSSVM model. Modeling with this method can achieve high precision if the training samples are reliable. The sampling data used for landslide displacement prediction are continuous and mutually dependent landslide data which are applicable to or feasible for the specific method. In this paper, the periodic component displacement is predicted by the GA-LSSVM model, which has higher accuracy than other models due to the consideration of the external environmental factors and its advantage in determining the unknown parameters that have great consistent between the predicted data and the measured data. MATLAB software is used to execute the model. The flowchart of the GA-LSSVM model is presented in Fig. 2.

\section{Case study: Shuping landslide}

\subsection{Geological conditions}

The Shuping landslide is located in the town of Shazhenxi, Zigui Country, Hubei Province, China, near the Yangtze River and approximately $47 \mathrm{~km}$ into the upper reach of Three Gorges Dam (Fig. 3). The sliding direction of Shuping landslide is $\mathrm{N} 11^{\circ} \mathrm{E}$, and the landslide is displayed as a sector on a topographic map (Fig. 3). The reservoir water level in Fig. 3 is $166 \mathrm{~m}$. The topography is relatively flat, with a mean slope angle of $22^{\circ}$. The highest elevation of the landslide is $400 \mathrm{~m}$ above sea level. The head scarp of the landslide reaches to the riverbed of the Yangtze River at $60 \mathrm{~m}$ in elevation. The landslide covers an area of approximately $54 \times 10^{4} \mathrm{~m}^{2}$, with an average length of $800 \mathrm{~m}$ in the longitudinal direction and an average length of $670 \mathrm{~m}$ in the transverse direction. The landslide volume is $2070 \times 10^{4} \mathrm{~m}^{3}$, with an average sliding surface depth of $40 \mathrm{~m}$ (Fig. 4). Figure 4 shows the eight GPS 

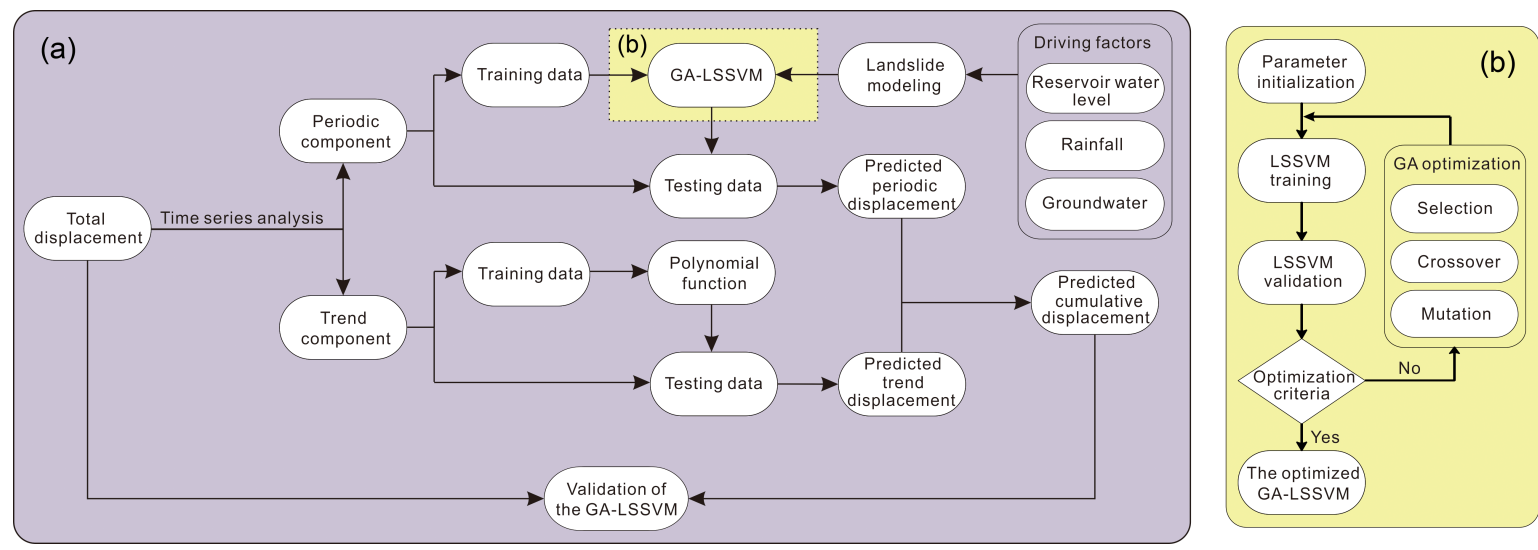

Figure 2. The basic flowchart of the GA-LSSVM model, including the validation of the model and the establishment of the GA-LSSVM model.
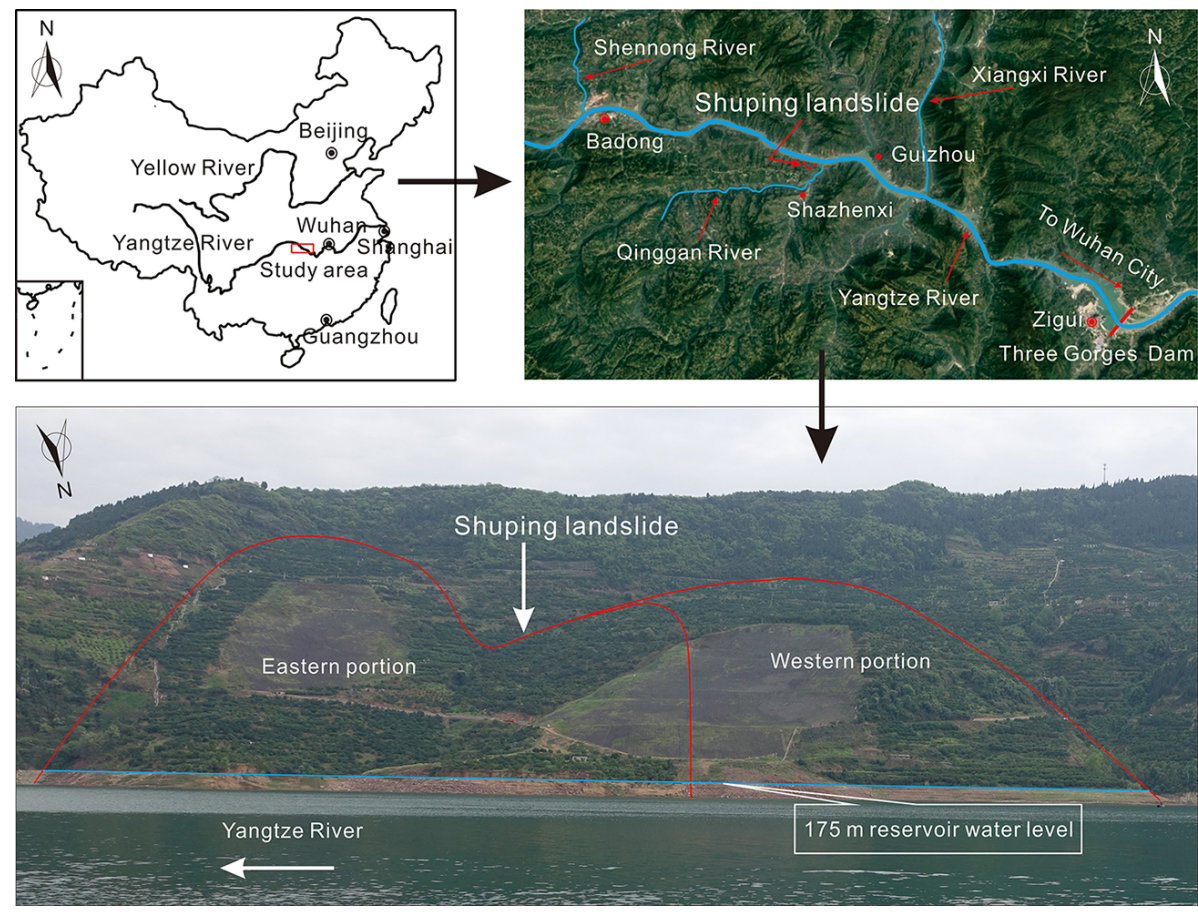

Figure 3. Location of the study area and panorama of the Shuping landslide and landslide subzones.

monitoring stations installed on the ground surface of the landslide, as well as four inclinometer monitoring holes. The bedrock is mainly sandy mudstone. The strata comprise the Triassic Badong formation. The dip direction of the bedrock is between 120 and $165^{\circ}$, and the dip angle is between 10 and $35^{\circ}$. The landslide is divided into an eastern portion and a western portion, and the materials of the landslide mainly include Quaternary deposits, soils containing silty clay and rock fragments with a loose and disorderly structure (Fig. 5). Figure 5 shows a longitudinal section of the eastern portion of the landslide. We can see from Fig. 5 that the sliding sur- face located between the deposits and the bedrock is steep in the upper area.

Underground moisture beneath the landslide is primarily groundwater flowing through loose media that include colluviums and deposits. Landslide deformation became more active after water storage began in Three Gorges Reservoir in June 2003. Various external factors affect the landslide displacement, including rainfall, the reservoir water level, surface water infiltration and groundwater. 


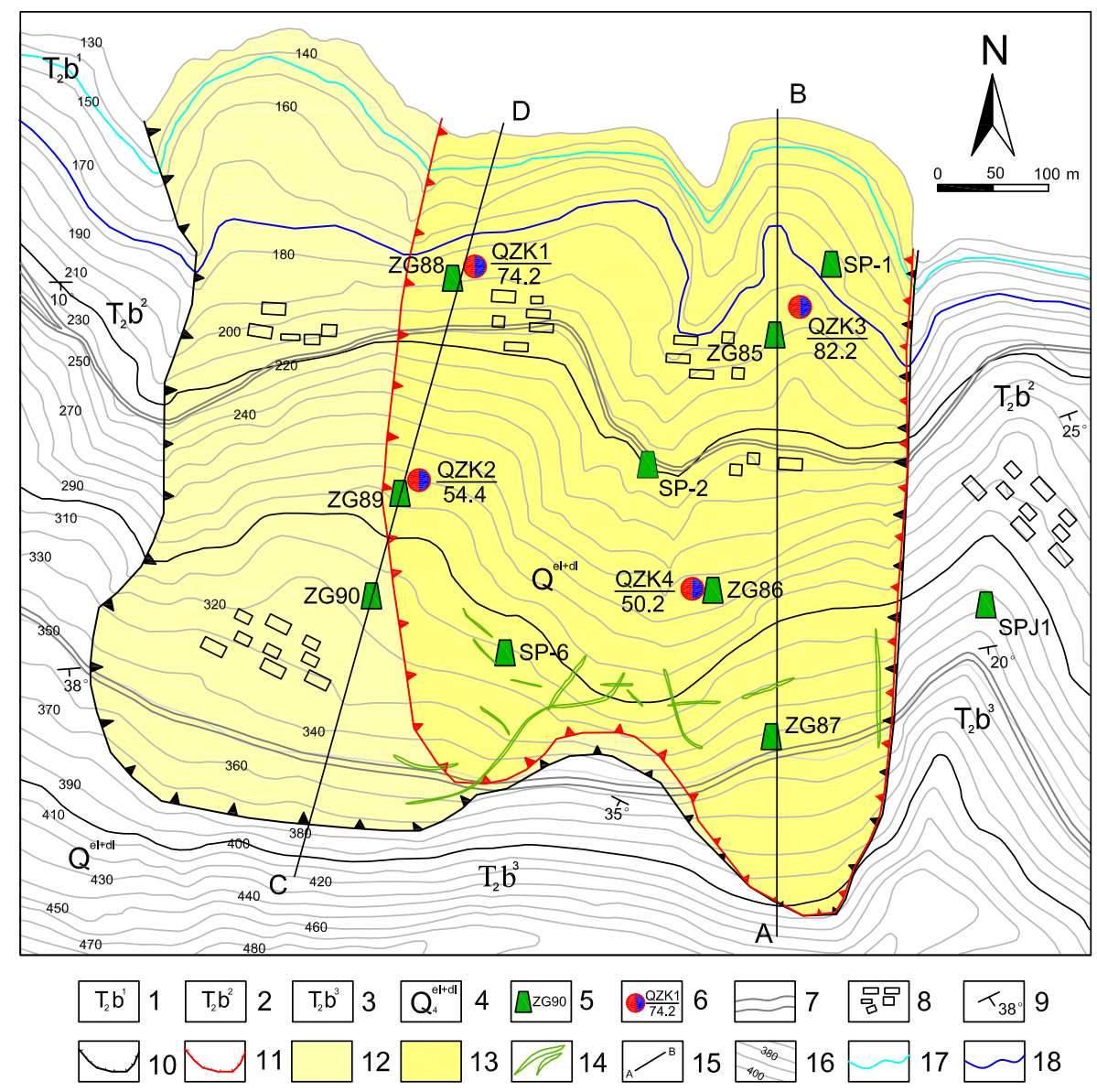

Figure 4. Geology and deformation monitoring map of Shuping landslide. (1) Middle Triassic Badong formation section; (1, 2) Middle Triassic Badong formation section; (2, 3) Middle Triassic Badong formation section; (3, 4) Quaternary colluviums; (5) GPS monitoring stations and number; (6) inclinometer monitoring hole and its depth (the unit of depth is the meter); (7) roads; (8) houses; (9) lithology orientation; (10) landslide boundary; (11) main sliding boundary; (12) western portion zone; (13) eastern portion zone; (14) cracks; (15) longitudinal section; (16) counter line; (17) reservoir water level (145 m); (18) reservoir water level (175 m).

\subsection{Monitoring data and deformation characteristics of the landslide}

Field investigations revealed that there was no obvious deformation of the landslide before the first impoundment of the reservoir on 15 June 2003. However, cracking occurred in roads and houses after the first impoundment. Monitoring stations were installed to measure the deformation characteristics and the stability of the landslide and to observe the interactions between different portions of the landslide. The monitoring methods include geodetic surveys, drilling, meteorological observations and geological investigations. Thus, the development processes and evolution of the landslide can be analyzed quantitatively using monitoring data from eight monitoring stations and four inclinometer monitoring holes located along the longitudinal direction of the landslide (ZG85 to ZG90, SP-2 and SP-6, and QZK1 to QZK4 in Fig. 4).
Figure 6 shows the monitoring results between July 2003 and October 2013, including rainfall and reservoir water level, which exhibit near-episodic movement characteristics after the first impoundment. The displacements in the middle (ZG86) and head scarp (ZG85) areas were greater than that in the back scarp (ZG87) area of longitudinal section A-B, and the displacements in the head scarp (ZG88) and middle (ZG89) areas were greater than that in the back scarp (ZG90) area in the western zone. These observations suggest that landslide displacements increased steadily, and Shuping landslide displayed retrograde-style deformation from the lower part to the upper part. The cumulative displacements at the monitoring stations located in the rear areas were relatively low, with an average value of $880 \mathrm{~mm}$, and the cumulative displacements at the monitoring stations located in the middle-frontal areas were very high, with an average value of $3890 \mathrm{~mm}$. Overall, landslide deformation in the eastern zone was greater than that in the western zone. Based on the reservoir water level data and the displacements 


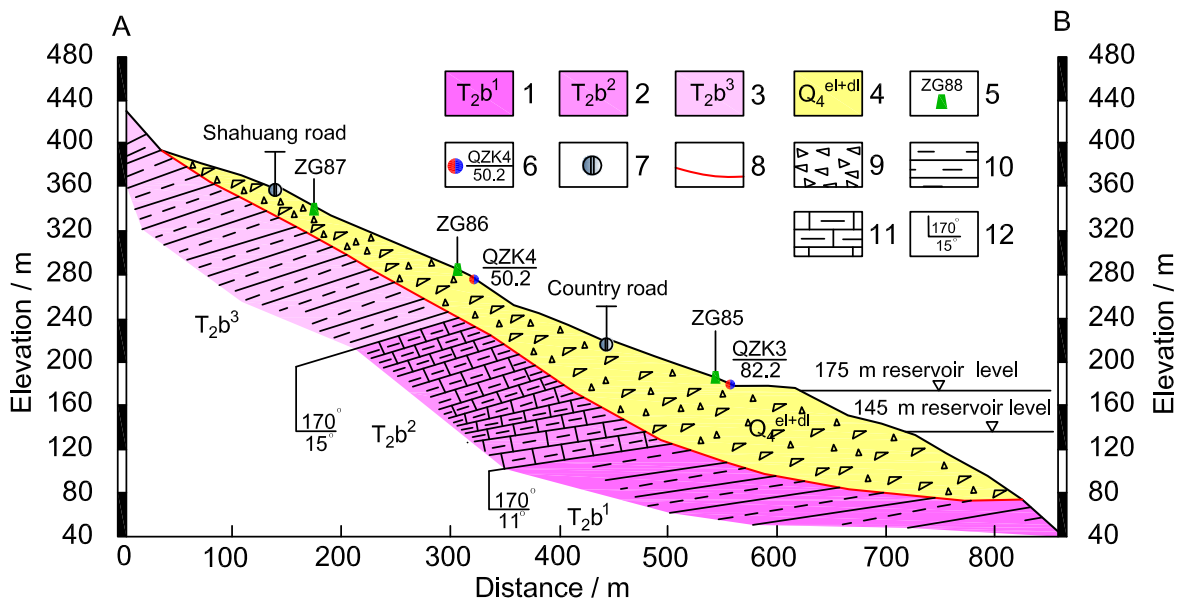

Figure 5. Geological longitudinal section (line A-B in Fig. 4) of Shuping landslide. (1) Middle Triassic Badong formation section; (1, 2) Middle Triassic Badong formation section; (2, 3) Middle Triassic Badong formation section; (3, 4) Quaternary colluviums; (5) GPS monitoring stations and number; (6) inclinometer monitoring hole and its depth (the unit of depth is the meter); (7) roads; (8) sliding zone; (9) colluvial gravel soil; (10) silty mudstone; (11) argillaceous limestone; (12) lithology orientation.

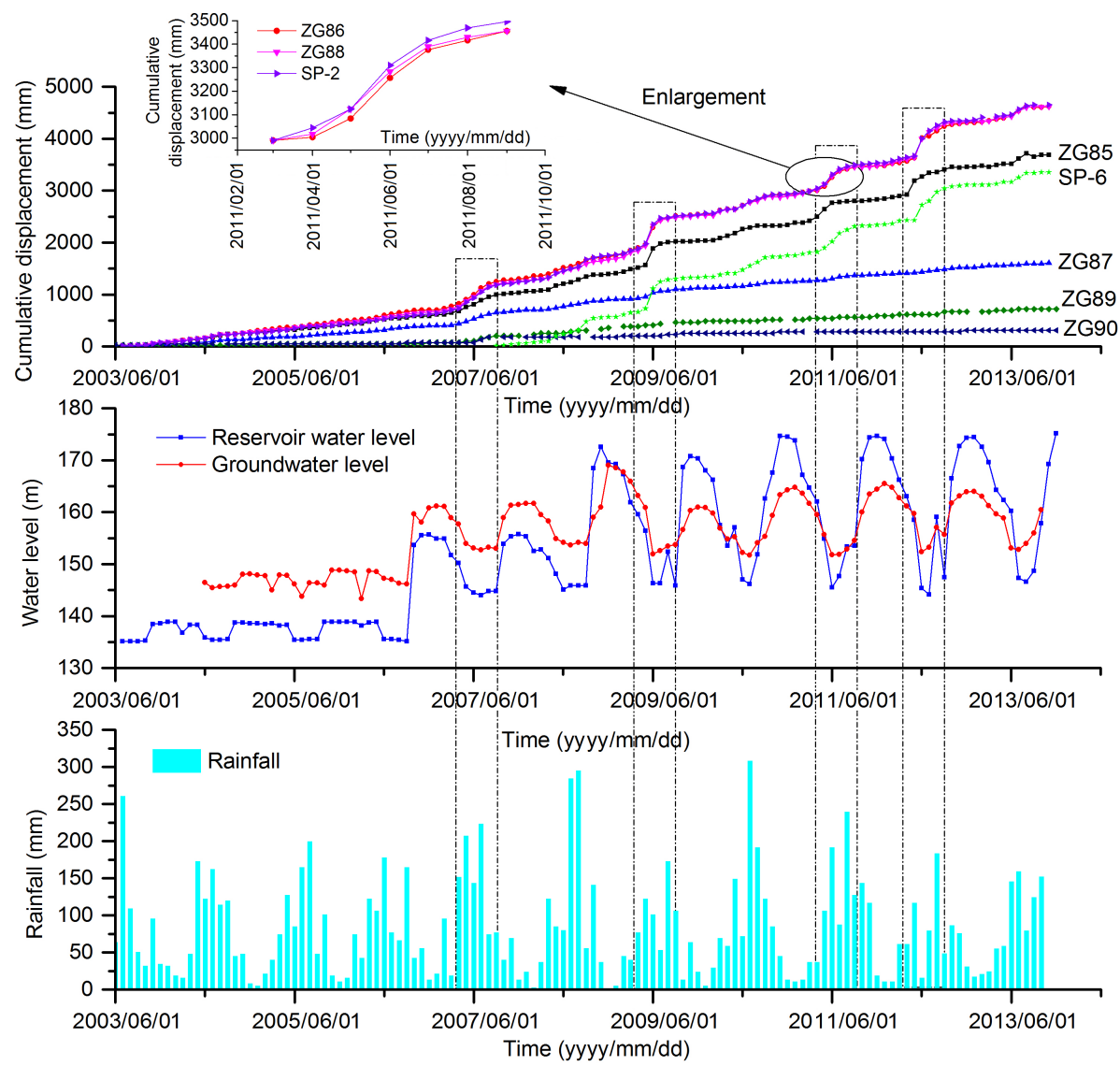

Figure 6. The relationships between rainfall, reservoir water level and displacement.

measured at eight monitoring stations, the cumulative displacement rate increased after the initial impoundment. Due to the increased rainfall and decreased reservoir water level between April and August each year, the cumulative displacement rises rapidly. Notable landslide accelerations can be observed in 2007, 2009, 2011 and 2012. The variations 


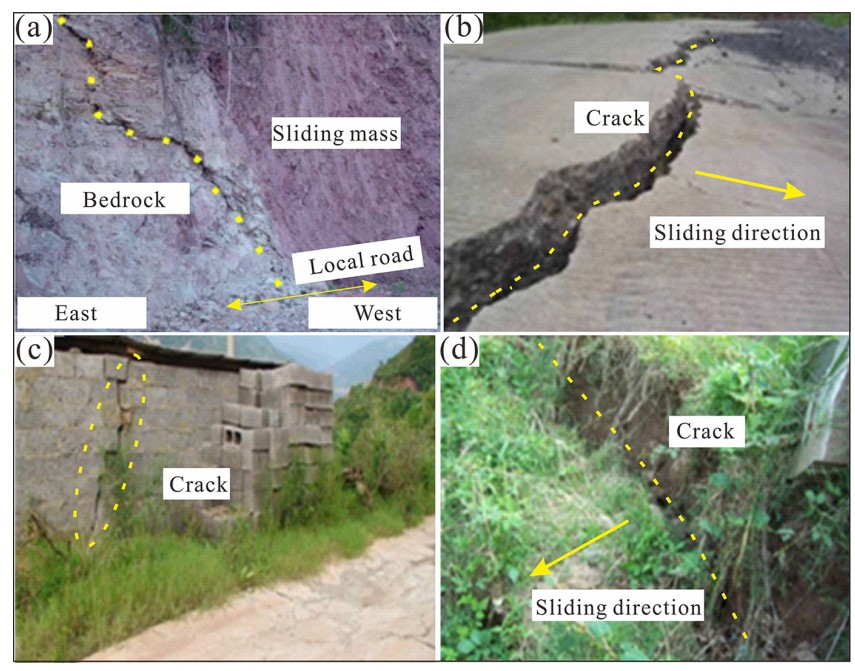

Figure 7. Photographs of the ground cracks in the landslide (Ren et al., 2015): (a) crack in the middle of the landslide on the outside of the local road, (b) failure state of the local road, (c) wall cracking and subsidence in the eastern portion and (d) the tension cracks in the eastern portion.

in reservoir water level and heavy rainfall increase porewater pressure and reduce the effective stress in the slope. In addition, the uplift pressure, hydrostatic pressure and hydrodynamic pressure acting on the landslide changed periodically. As a result, the landslide stability decreased and the deformation increased.

Many deformation or failure phenomena were observed in the Shuping landslide. In June 2003, a crack was generated in the middle part of the landslide on the outside of a local road, as shown in Fig. 7a. In 2006, the reservoir water level increased to $156 \mathrm{~m}$ for the first time. Figure $7 \mathrm{~b}$ illustrates that the crack gradually extended to a width of $10 \mathrm{~cm}$ within 3 months of completing the road in April 2007. In August 2008, after a heavy storm occurred, deformation and tension cracks developed in the eastern portion of the landslide and impacted houses, as shown in Fig. 7c. Since 2008, the reservoir water level has increased gradually to $172 \mathrm{~m}$ in October. In June 2009, the western portion of the landslide started cracking, with a maximum crack width of $20 \mathrm{~cm}$ and depth of $20-50 \mathrm{~cm}$. In addition, several tension cracks formed at the eastern landslide boundary. The tension cracks in the eastern portion are shown in Fig. 7d. In recent years, the cumulative deformation rate has remained low due to the relatively stable reservoir water level, which has fluctuated between 145 and $175 \mathrm{~m}$.

Therefore, the landslide deformation characteristics suggest that deformation in the western portion of the landslide is smaller than that in the eastern portion, and the Shuping landslide is affected by reservoir water level fluctuations and rainfall. When rainfall increases abruptly and the reservoir water level drops between April and August annually, the landslide becomes active, which increases landslide deformation. In other conditions, the landslide undergoes slow deformation at a constant speed.

In addition, groundwater, which is regarded as an active geologic agent, is one of the main factors that induces landslide instability. The relationships between the periodic displacement and the groundwater and the reservoir water level are illustrated in Fig. 6. In the rising phase of reservoir water level, the groundwater level gradually increases, with a slight lag behind the increase in the reservoir water level. The groundwater remains high enough for ongoing movement to continue. Conversely, the groundwater level decreases in the declining phase of the reservoir water level. Moreover, the uplift pressure and seepage force of groundwater are dynamic processes that affect landslide stability. Therefore, groundwater influences displacement.

Overall, the reservoir water level, rainfall and groundwater are the major factors that influence the displacement of the Shuping landslide. The landslide displacement obviously increases when the reservoir water level decreases or when rainfall is heavy and continuous because the excess porewater pressure reduces the mean effective stress at the landslide shear surface making it more susceptible to movement.

During the period between June 2003 to June 2009, monitoring data show that the landslide deformation differences are manifested in the ground surface, and they display vertically distributed characteristics with elevation. In conclusion, the surface displacements below $200 \mathrm{~m}$ in elevation are larger than those above $200 \mathrm{~m}$, and deformation is largest close to $175 \mathrm{~m}$, which is the upper limit of the reservoir water level. This observation is due to the considerable influence of fluctuations in the reservoir water level on the landslide area below $200 \mathrm{~m}$. The deep deformation of the landslide exhibited distinct differences at different depths, as shown in Fig. 8. Inclinometer monitoring holes QZK3, QZK4, QZK1 and QZK2, which are located in the western portion of the landslide, exhibited small deformation and similar deformation trends. Thus, their lateral displacement curves are not presented, and only the curves of QZK3 and QZK4 are illustrated in this paper. The figures show that the sliding zones of QZK3 and QZK4 are located at elevations of 70 and $30 \mathrm{~m}$, respectively. Furthermore, the displacement change in the shallow sliding zones of both QZK3 and QZK4 is larger than that in the deep sliding zone.

\section{Landslide displacement prediction}

Based on the analysis of the deformation characteristics of Shuping landslide and the GA-LSSVM model above and due to the obvious nonlinear and episodic movement deformation characteristics of monitoring stations ZG85, ZG86 and ZG87, we select only these stations along longitudinal section A-B to verify and establish the prediction model. The model information includes rainfall, the reservoir water level, 

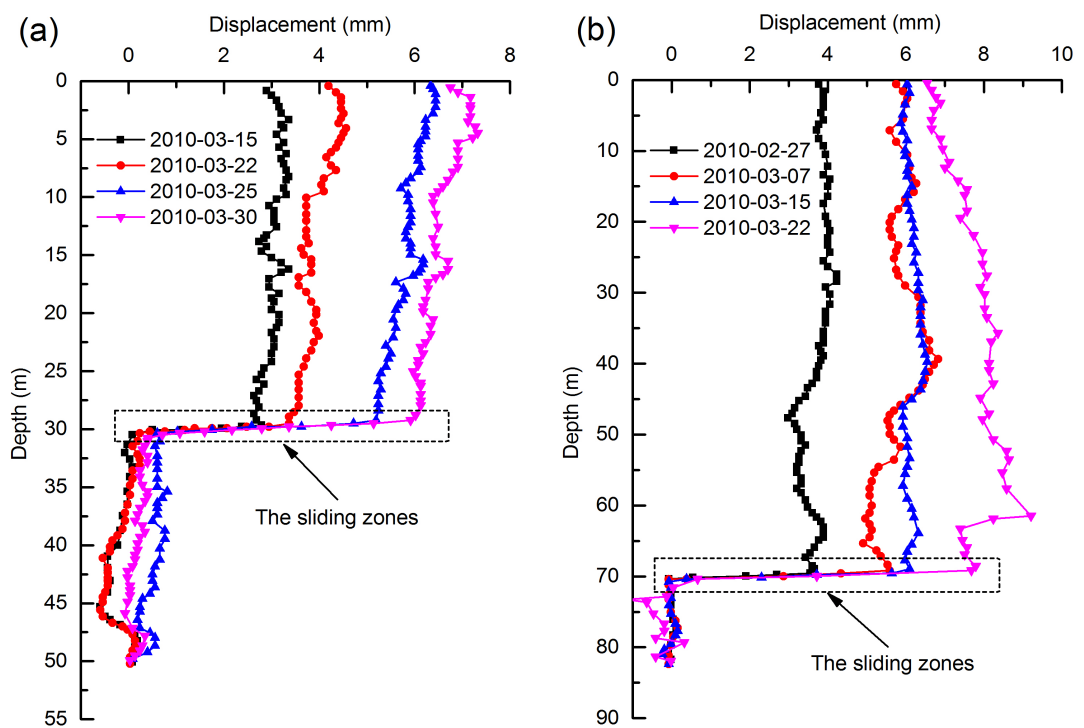

Figure 8. Lateral displacements of Shuping landslide: (a) inclinometer monitoring hole QZK3 and (b) inclinometer monitoring hole QZK4.
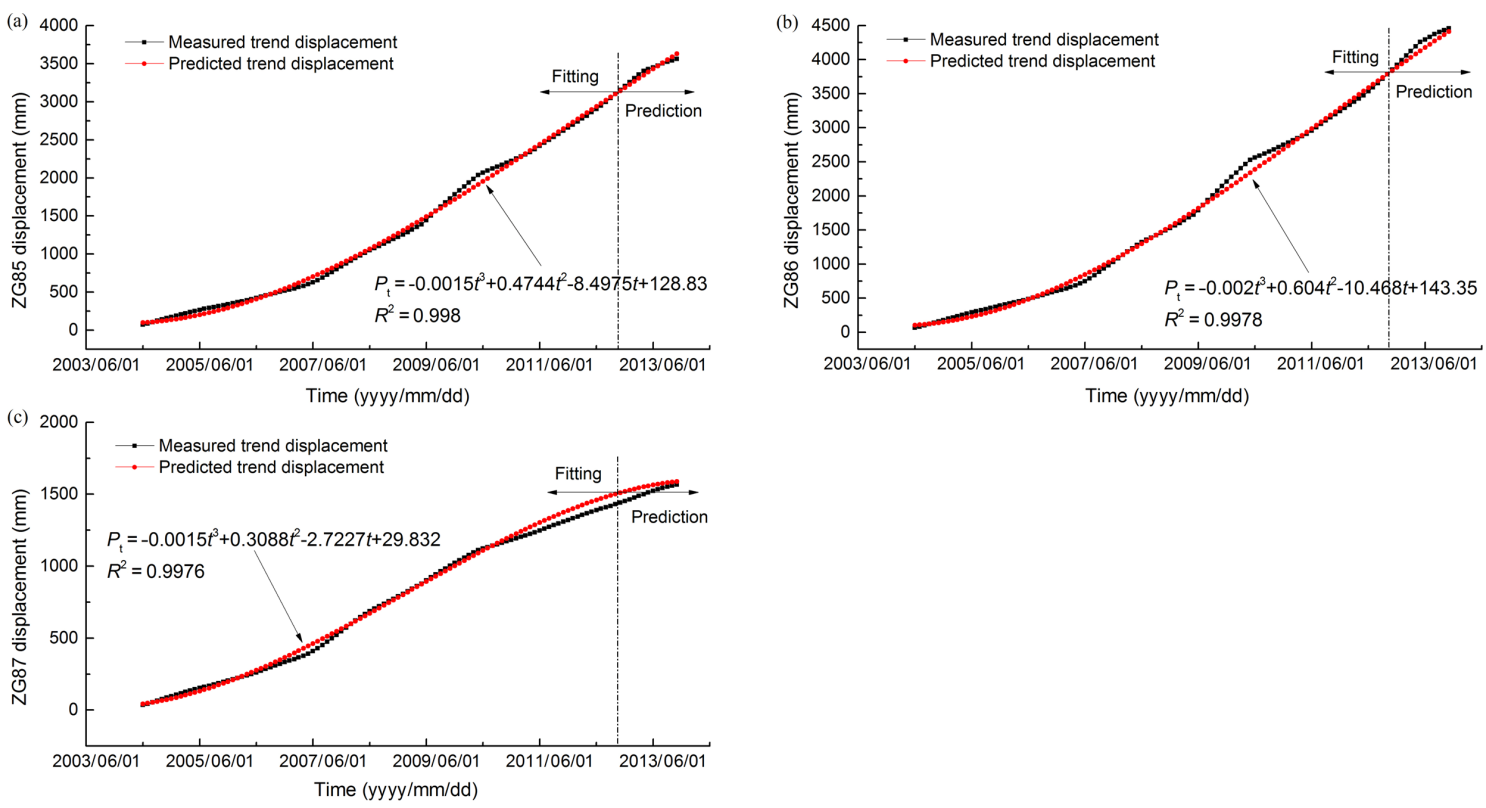

Figure 9. Measured and predicted trend component displacement of Shuping landslide.

human activities and the long-term behavior of Shuping landslide. Because the integrity of the data collected at monitoring points has an effect on the displacement prediction, the monitoring data from July 2003 to October 2013 are selected to explore landslide deformation. The data before October 2012 are used to train the GA-LSSVM model, and the data after October 2012 are used to test the model.

\subsection{Prediction of the trend component displacement}

Due to the scheduling period of the reservoir and the rainfall cycle, we choose 12 months as the moving average pe- riod. Because the curves of the trend component displacement versus time have quasi-linear and incremental characteristics, we use polynomial functions to fit these curves and provide the best-fitted results. The predicted and measured results of the trend component displacement at monitoring stations ZG85, ZG86 and ZG87 are shown in Figs. 9a$\mathrm{c}$, respectively. They indicate that the polynomial function provides good prediction performance for the trend component displacement and the fitted functions are expressed in Eqs. (13), (14) and (15). It is noted that correlation coefficient $\left(R^{2}\right)$ is a statistical index used to reflect the degree of 


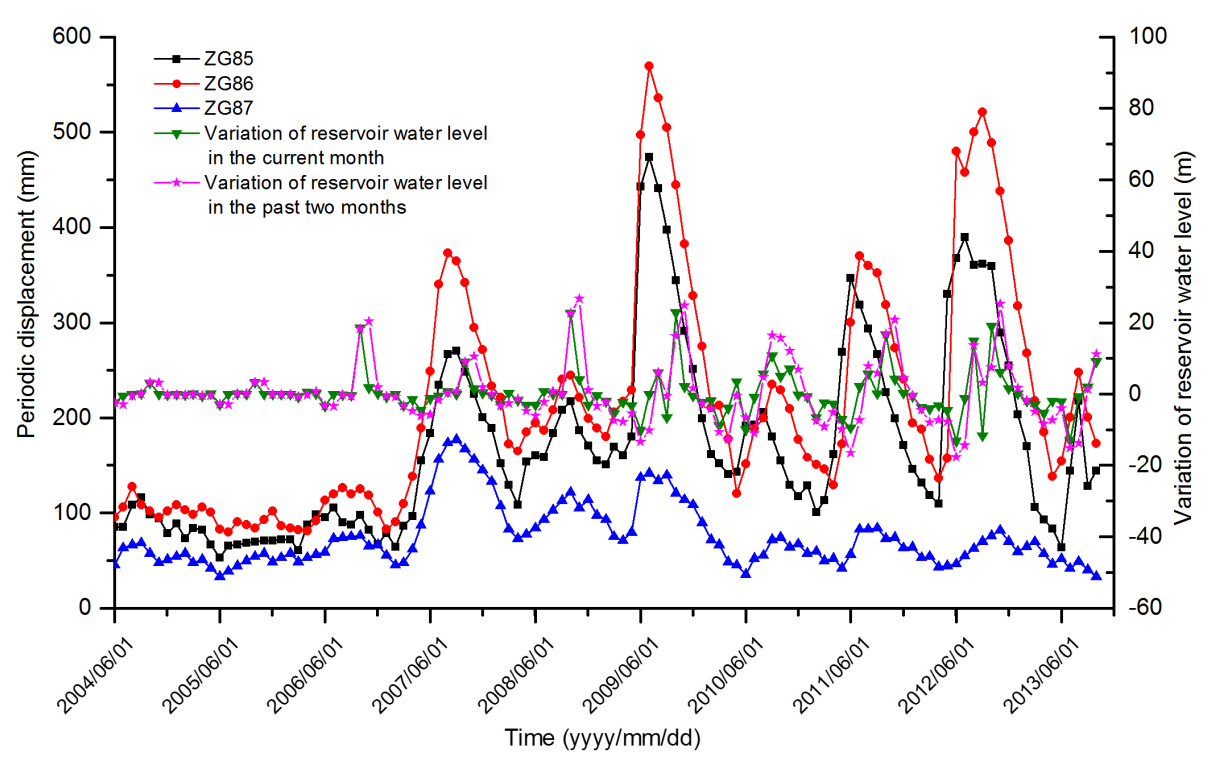

Figure 10. The relationship between reservoir water level and the periodic displacement at GPS monitoring stations.

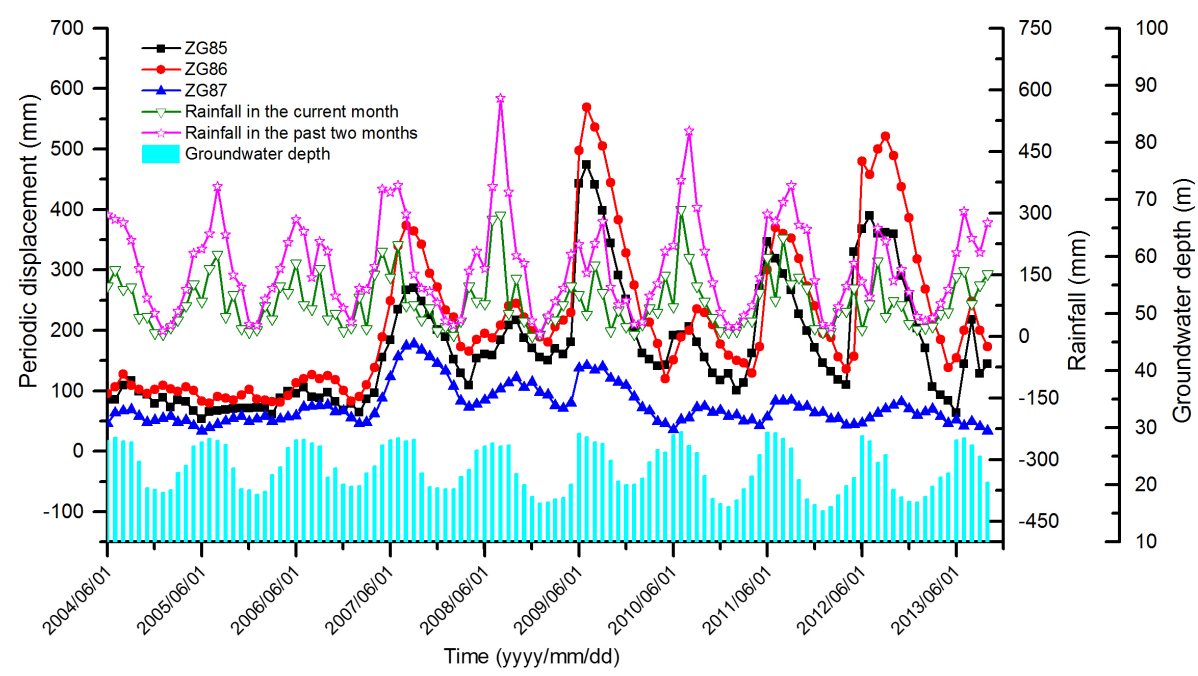

Figure 11. The relationships between rainfall, groundwater depth and periodic displacement at GPS monitoring stations.

correlation between variables and it is calculated according to the predictive part of the data.

$$
\begin{aligned}
& p_{t}=-0.0015 t^{3}+0.4744 t^{2}-8.4975 t+128.83 R^{2}=0.9980 \\
& p_{t}=-0.002 t^{3}+0.604 t^{2}-10.468 t+143.35 R^{2}=0.9978 \\
& p_{t}=-0.0015 t^{3}+0.3088 t^{2}-2.7227 t+29.832 R^{2}=0.9976
\end{aligned}
$$

\subsection{The predicted periodic component displacement}

The periodic component displacement is determined by subtracting the extracted trend component displacement from the cumulative displacement. The periodic displacement and the major influencing factors are illustrated in Figs. 10 and
11. The variations in the periodic displacement are consistent with those in the influencing factors. The reservoir water level, rainfall and groundwater significantly influence the periodic displacement. For example, large periodic displacement can be observed in July 2009 and September 2012 when the landslide was affected by heavy rainfall and large variations in reservoir water level. Although the variation in reservoir water level was small before April 2007, the periodic displacement still exhibited small fluctuations due to the effects of rainfall and groundwater. This behavior could be explained in terms of stress changes within the landslide in that the rainfall events cause increased porewater pressures in the landslide shear zone which reduced the effective stress and increased instability. After April 2007, several dis- 
Table 1. Relational grades between input variables and the periodic displacements.

\begin{tabular}{|c|c|c|c|c|c|c|}
\hline \multirow[b]{2}{*}{$\begin{array}{l}\text { Monitoring } \\
\text { station }\end{array}$} & \multicolumn{6}{|c|}{ Relational grade } \\
\hline & $\begin{array}{l}\text { The cumulative } \\
\text { rainfall in the }\end{array}$ & $\begin{array}{l}\text { The cumulative } \\
\text { rainfall in the }\end{array}$ & $\begin{array}{r}\text { The } \\
\text { reservoir }\end{array}$ & $\begin{array}{l}\text { The variation of } \\
\text { the reservoir water level } \\
\text { in the current month }\end{array}$ & $\begin{array}{l}\text { The variation of } \\
\text { the reservoir water level } \\
\text { in the past } 2 \text { months }\end{array}$ & $\begin{array}{r}\text { Groundwater } \\
\text { depth }\end{array}$ \\
\hline ZG85 & 0.700 & 0.705 & 0.763 & 0.797 & 0.768 & 0.718 \\
\hline ZG86 & 0.682 & 0.691 & 0.756 & 0.794 & 0.770 & 0.714 \\
\hline ZG87 & 0.692 & 0.705 & 0.724 & 0.794 & 0.780 & 0.720 \\
\hline
\end{tabular}

Table 2. Optimal parameters of the LSSVM model.

\begin{tabular}{lrrr}
\hline Number & $\begin{array}{r}\text { Monitoring } \\
\text { station }\end{array}$ & $C$ & $\sigma$ \\
\hline 1 & ZG85 & 11.8234 & 6.4122 \\
2 & ZG86 & 4.7346 & 8.0545 \\
3 & ZG87 & 39.7819 & 5.7981 \\
\hline
\end{tabular}

tinct peaks can be observed in the periodic displacement time curves during periods of decreasing reservoir water level. For example, the periodic displacement increased from May to July 2009 and from May to September 2012. However, when the reservoir water level increased from 145 to $175 \mathrm{~m}$, the periodic displacement gradually decreased. The main reason for the above conditions was that the rise of the reservoir water level increased the confining stress on the surface of the landslide and the hydrodynamic pressure, the direction of which was toward the interior of sliding body. Similarly, the lowering of the reservoir water level reduced the confining stress whilst porewater pressures were still high which would promote accelerated movement. The periodicity of the rainfall also affected the displacement rate. The periodic displacement increased with increasing rainfall and reached a peak value in summer, which reflects a certain lag. For example, during February and June 2007, the reservoir water level decreased $10 \mathrm{~m}$, while the rainfall was $297.7 \mathrm{~mm}$ during the subsequent 2 months, which should have been enough to trigger landslide deformation. Therefore, the decrease of the reservoir water level continued to have an effect on displacement and there was also a lag effect, which means the displacement did not occur as soon as the reservoir water level decreased but was delayed.

At the head scarp of the landslide at an elevation of $181 \mathrm{~m}$, groundwater depth was measured by water level sensor within inclinometer monitoring hole QZK3. The change in groundwater depth exhibited considerable agreement with rainfall and reservoir water level fluctuations, with a slight lag observed for the latter. When the reservoir water level and the groundwater depth were decreasing at different speeds, the groundwater will respond with a lag in relation to the variations of the reservoir water level. Due to the slight lag with the reservoir water level, groundwater increased the hydrodynamic pressure during periods when the reservoir water level decreased or remained stable, which resulted in continuous deformation of the landslide. Therefore, in the shallow groundwater zone, the periodic displacements measured at the three monitoring stations exhibited considerable fluctuations. In conclusion, the results in Figs. 10 and 11 indicate that the reservoir water level exerts the most influences on the displacement rate.

The grey relational grade can represent the proximity degree between two series. If the trends in the two series are consistent or the degree of synchronous change is high, then the relational grade associated with system development is large. Otherwise, the relational grade is small. To remove the influence of dimensional data, data series must be normalized before calculating the relational grades, including the series of periodic displacement, rainfall and reservoir water level changes. The normalized formula can be expressed by Eq. (16):

$\bar{y}=\frac{y-y_{\min }}{y_{\max }-y_{\min }}$,

where $\bar{y}$ is the normalized value, $y$ is the original value, $y_{\max }$ is the maximum value of the data series and $y_{\min }$ is the minimum value of the data series.

The grey relational coefficient of each data series and reference data series at each moment can be calculated as the following:

$\gamma\left(y_{0}(k), y_{i}(k)\right)=\frac{\Delta \min +\rho \Delta \max }{\Delta_{o j}(k)+\rho \Delta \max }$,

where $j=1,2 \ldots n ; k=1,2 \ldots m, n$ is the number of data series items and $m$ is the number of parameters, $y_{0}(k)$ is the reference data series, $y_{j}(k)$ is the series after data preprocessing, $\Delta_{o j}(k)=\left\|y_{0}(k)-y_{j}(k)\right\|$ is the absolute value of the difference between $y_{0}(k)$ and $y_{j}(k), \Delta \min =$

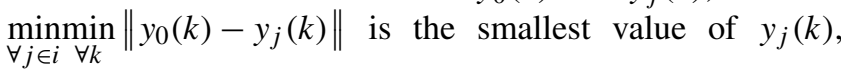
$\Delta \max =\max _{\forall j \in i} \max _{\forall k}\left\|y_{0}(k)-y_{j}(k)\right\|$ is the largest value of $y_{j}(k)$ and $\rho$ is the distinguishing coefficient, $\rho \in[0,1]$. The smaller a value of $\rho$ is, the larger the distinguished ability is. $\rho=0.5$ is generally used in the paper. 
Table 3. Comparison between the predicted values of cumulative displacement and measured values at monitoring station ZG85.

\begin{tabular}{lr|rr|rr|r|r}
\hline & Measured & \multicolumn{2}{|c|}{ GA-LSSVM } & \multicolumn{2}{|c}{ GRNN } & \multicolumn{2}{c}{ BP } \\
\cline { 3 - 8 } Time & $\begin{array}{r}\text { value (mm) } \\
\text { value (mm) }\end{array}$ & $\begin{array}{r}\text { Predicted } \\
\text { error (\%) }\end{array}$ & $\begin{array}{r}\text { Relative } \\
\text { value (mm) }\end{array}$ & $\begin{array}{r}\text { Predicted } \\
\text { error (\%) }\end{array}$ & $\begin{array}{r}\text { Relative } \\
\text { value (mm) } \\
\text { error (\%) }\end{array}$ & Predicted & Relative \\
\hline $2012 / 10 / 01$ & 3460.208 & 3399.937 & 1.74 & 3324.829 & 3.91 & 3315.157 & 4.38 \\
$2012 / 11 / 01$ & 3442.907 & 3389.608 & 1.55 & 3337.861 & 3.05 & 3349.827 & 2.78 \\
$2012 / 12 / 01$ & 3460.208 & 3379.418 & 2.33 & 3336.503 & 3.58 & 3393.732 & 1.96 \\
$2013 / 01 / 01$ & 3460.208 & 3406.014 & 1.57 & 3371.989 & 2.55 & 3427.727 & 0.95 \\
$2013 / 02 / 01$ & 3477.509 & 3446.374 & 0.90 & 3410.133 & 1.94 & 3452.011 & 0.74 \\
$2013 / 03 / 01$ & 3460.208 & 3462.169 & 0.06 & 3449.721 & 0.30 & 3482.668 & 0.64 \\
$2013 / 04 / 01$ & 3494.81 & 3485.798 & 0.26 & 3502.356 & 0.22 & 3543.963 & 1.39 \\
$2013 / 05 / 01$ & 3512.111 & 3524.423 & 0.35 & 3555.754 & 1.24 & 3625.738 & 3.13 \\
$2013 / 06 / 01$ & 3512.111 & 3591.262 & 2.25 & 3684.274 & 4.90 & 3699.022 & 5.05 \\
$2013 / 07 / 01$ & 3615.917 & 3695.444 & 2.20 & 3802.473 & 5.16 & 3738.225 & 3.27 \\
$2013 / 08 / 01$ & 3719.723 & 3747.513 & 0.75 & 3830.496 & 2.98 & 3779.618 & 1.58 \\
$2013 / 09 / 01$ & 3650.519 & 3740.002 & 2.45 & 3832.151 & 4.98 & 3825.664 & 4.58 \\
$2013 / 10 / 01$ & 3685.121 & 3795.259 & 2.99 & 3877.587 & 5.22 & 3848.299 & 4.24 \\
\hline
\end{tabular}

Table 4. Comparison between the predicted values of cumulative displacement and measured values at monitoring station ZG86.

\begin{tabular}{lr|rr|rr|rr}
\hline & Measured & \multicolumn{2}{|c|}{ GA-LSSVM } & \multicolumn{2}{|c|}{ GRNN } & \multicolumn{2}{c}{ BP } \\
\cline { 3 - 8 } Time & $\begin{array}{r}\text { value (mm) } \\
\text { error (\%) }\end{array}$ & $\begin{array}{r}\text { Predicted } \\
\text { value (mm) }\end{array}$ & $\begin{array}{r}\text { Relative } \\
\text { error (\%) }\end{array}$ & $\begin{array}{r}\text { Predicted } \\
\text { value (mm) }\end{array}$ & $\begin{array}{r}\text { Relative } \\
\text { error (\%) }\end{array}$ & Predicted & Relative \\
\hline $2012 / 10 / 01$ & 4273.356 & 4183.984 & 2.09 & 4094.396 & 4.19 & 4096.849 & 4.13 \\
$2012 / 11 / 01$ & 4290.657 & 4201.857 & 2.07 & 4104.93 & 4.33 & 4124.839 & 3.86 \\
$2012 / 12 / 01$ & 4307.958 & 4149.796 & 3.67 & 4094.607 & 4.95 & 4091.602 & 5.02 \\
$2013 / 01 / 01$ & 4307.958 & 4164.444 & 3.33 & 4130.77 & 4.11 & 4133.425 & 4.05 \\
$2013 / 02 / 01$ & 4325.26 & 4192.775 & 3.06 & 4172.182 & 3.54 & 4186.816 & 3.20 \\
$2013 / 03 / 01$ & 4342.561 & 4256.46 & 1.98 & 4212.082 & 3.00 & 4246.771 & 2.21 \\
$2013 / 04 / 01$ & 4377.163 & 4317.892 & 1.35 & 4247.617 & 2.96 & 4312.109 & 1.49 \\
$2013 / 05 / 01$ & 4394.464 & 4326.232 & 1.55 & 4297.626 & 2.20 & 4386.529 & 0.18 \\
$2013 / 06 / 01$ & 4446.367 & 4388.693 & 1.30 & 4403.464 & 0.96 & 4523.094 & 1.73 \\
$2013 / 07 / 01$ & 4532.872 & 4495.404 & 0.83 & 4535.948 & 0.07 & 4607.573 & 1.65 \\
$2013 / 08 / 01$ & 4619.377 & 4609.902 & 0.21 & 4626.647 & 0.16 & 4656.543 & 0.80 \\
$2013 / 09 / 01$ & 4602.076 & 4579.721 & 0.49 & 4628.676 & 0.58 & 4661.733 & 1.30 \\
$2013 / 10 / 01$ & 4602.076 & 4592.204 & 0.21 & 4754.15 & 3.30 & 4713.128 & 2.41 \\
\hline
\end{tabular}

Then the average value of the grey relational coefficients is regarded as the grey relational grade (Tosun, 2006). Thus, the grey relational grade is generated as follows:

$\overline{\gamma_{j}}=\frac{1}{k} \sum_{i=1}^{m} \gamma_{i j}$,

where $\overline{\gamma_{j}}$ is the grey relational grade for the $j$ th data series.

Based on the grey relational analysis method, the relational grades between the influencing factors and the periodic displacements are shown in Table 1. We can use the large grey relational grades as the input variables in the GALSSVM model. When the relational grade is larger than 0.6, the influencing factor is closely correlated with the periodic displacement, which suggests that the selection of the influencing factor for predicting periodic displacement is reason- able (Wang, 2003; Wang et al., 2004). In addition, based on research on the relationship between reservoir water level and landslide or the relationship between rainfall and landslide, the variation of the reservoir water level or the cumulative rainfall in the current month and the past 2 months before landslide failure all have strong influences on landslide deformation rates. Therefore, comprehensively considering the characteristics of the periodic displacement and the relational grades between variables, the cumulative rainfall in the current month, the cumulative rainfall in the past 2 months, the reservoir water level, the variation in the reservoir water level in the current month and the variation in the reservoir water level in the past 2 months are selected as input variables. In addition, the infiltration of rainfall and reservoir water level changes the dynamic characteristics of groundwater in land- 
Table 5. Comparison between the predicted values of cumulative displacement and measured values at monitoring station ZG87.

\begin{tabular}{lr|rr|rr|rr}
\hline & Measured & \multicolumn{2}{|c|}{ GA-LSSVM } & \multicolumn{2}{|c}{ GRNN } & \multicolumn{2}{c}{ BP } \\
\cline { 3 - 8 } Time & $\begin{array}{r}\text { value (mm) } \\
\text { value (mm) }\end{array}$ & $\begin{array}{r}\text { Predicted } \\
\text { error (\%) }\end{array}$ & $\begin{array}{r}\text { Relative } \\
\text { value (mm) }\end{array}$ & $\begin{array}{r}\text { Predicted } \\
\text { error }(\%)\end{array}$ & $\begin{array}{r}\text { Relative } \\
\text { value (mm) } \\
\text { error }(\%)\end{array}$ & Predicted & Relative \\
\hline $2012 / 10 / 01$ & 1505.19 & 1561.869 & 3.77 & 1578.221 & 4.85 & 1583.026 & 5.17 \\
$2012 / 11 / 01$ & 1522.491 & 1580.602 & 3.82 & 1590.364 & 4.46 & 1597.352 & 4.92 \\
$2012 / 12 / 01$ & 1522.491 & 1580.359 & 3.80 & 1586.605 & 4.21 & 1591.506 & 4.53 \\
$2013 / 01 / 01$ & 1522.491 & 1581.923 & 3.90 & 1593.249 & 4.65 & 1600.855 & 5.15 \\
$2013 / 02 / 01$ & 1539.792 & 1585.652 & 2.98 & 1599.822 & 3.90 & 1606.609 & 4.34 \\
$2013 / 03 / 01$ & 1557.093 & 1600.959 & 2.82 & 1605.274 & 3.09 & 1617.769 & 3.90 \\
$2013 / 04 / 01$ & 1557.093 & 1601.648 & 2.86 & 1606.713 & 3.19 & 1606.812 & 3.19 \\
$2013 / 05 / 01$ & 1557.093 & 1608.744 & 3.32 & 1612.571 & 3.56 & 1615.702 & 3.76 \\
$2013 / 06 / 01$ & 1574.394 & 1620.881 & 2.95 & 1622.897 & 3.08 & 1618.934 & 2.83 \\
$2013 / 07 / 01$ & 1574.394 & 1620.703 & 2.94 & 1632.984 & 3.72 & 1623.904 & 3.14 \\
$2013 / 08 / 01$ & 1591.696 & 1631.651 & 2.51 & 1643.08 & 3.23 & 1637.051 & 2.85 \\
$2013 / 09 / 01$ & 1591.696 & 1630.511 & 2.44 & 1652.604 & 3.83 & 1647.566 & 3.51 \\
$2013 / 10 / 01$ & 1591.696 & 1633.119 & 2.60 & 1653.808 & 3.90 & 1653.139 & 3.86 \\
\hline
\end{tabular}

slide, which reflects the change of groundwater level. On the one hand, the change of groundwater level makes sliding mass or sliding zone in a dry and wet circulation state, which leads to changes in the physical and mechanical properties of the sliding mass or sliding zone. On the other hand, due to the change of groundwater level, the seepage force and the uplift pressure of groundwater acting on the landslide change dynamically. Hence, considering the influences of rainfall and reservoir water level on landslide displacement, and in order to make prediction performance more accurate, it is also necessary to select groundwater depth as input variable for landslide prediction. Moreover, the periodic component displacement is established as the output variable for use in the GA-LSSVM model.

The parameters of the LSSVM are optimized by the GA, including the best values of $C$ and $\sigma$. Table 2 shows the optimal parameters of the LSSVM. The maximum generation threshold of the GA is 200, and the population number is 20 . To validate the prediction ability of the GA-LSSVM model, we compare the results of generalized regression neural network (GRNN) and BP with two hidden layers with the result of the GA-LSSVM model. In this paper, the smoothing factor of the GRNN is 0.48 , and there are 10 nodes in one of the hidden layers and 11 nodes in the other hidden layer of the BP.

The prediction results of the periodic component displacement are shown in Fig. 12. The predicted values of the three prediction models and the measured values are consistent and illustrate similar trends. However, the predicted values obtained using the GA-LSSVM exhibit better agreement with observations than the other methods. Notably, the advantages of the model are clear from April 2013 to October 2013 in Fig. 12a and b, as the periodic component displacement exhibited good agreement with the major influencing factors during a period of heavy rainfall and large fluctuations in the reservoir water level. Though Fig. 12b does not match well, on the whole, its difference is less than the other two methods. Especially, in August and September 2013, the differences between predicted values and measured values are all $10 \mathrm{~mm}$. However, in terms of BP model, the differences between predicted values and measured values are 107 and $109 \mathrm{~mm}$, respectively, and their differences for GRNN model are 137 and $142 \mathrm{~mm}$, respectively.

\subsection{Predicted cumulative displacement}

The predicted cumulative displacement is determined from the sum of the predicted trend displacement and the predicted periodic displacement. The predicted cumulative displacements and the measured values are presented in Tables 3, 4 and 5 for monitoring station ZG85, ZG86 and ZG87, respectively. The results given in Tables 3, 4 and 5 suggest that the GA-LSSVM model has better prediction performance than the GRNN model and the BP model, with a smaller relative error. Comparisons between the predicted values of cumulative displacement and measured values are shown in Fig. 13. The diagonal line shows the best prediction result in Fig. 13. The results are underestimated if the predicted values are located below the diagonal line, whereas the predicted values located above the line are overestimated. The predicted values from all the monitoring stations show good consistency with the measured values, as shown in Fig. 13.

\section{Verification and error analyses}

Three loss functions are used to assess the prediction performance and accuracy of the proposed model: the root mean square error (RMSE), mean absolute error (MAE) and mean absolute percentage error (MAPE). Then, the optimal parameters with minimum error are used to train the LSSVM 
(a)

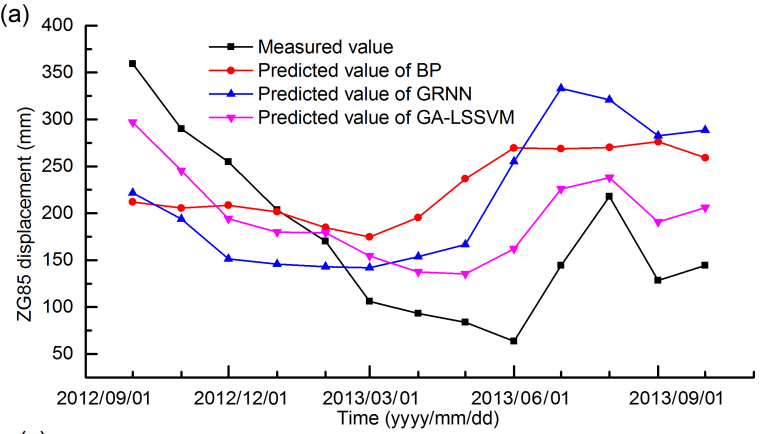

(c)

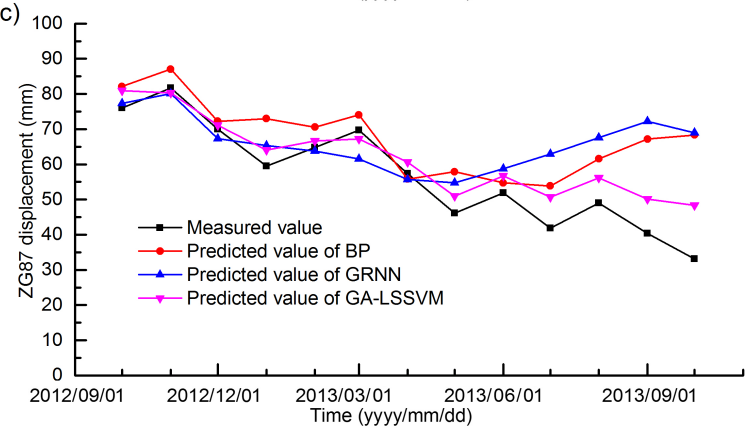

(b)

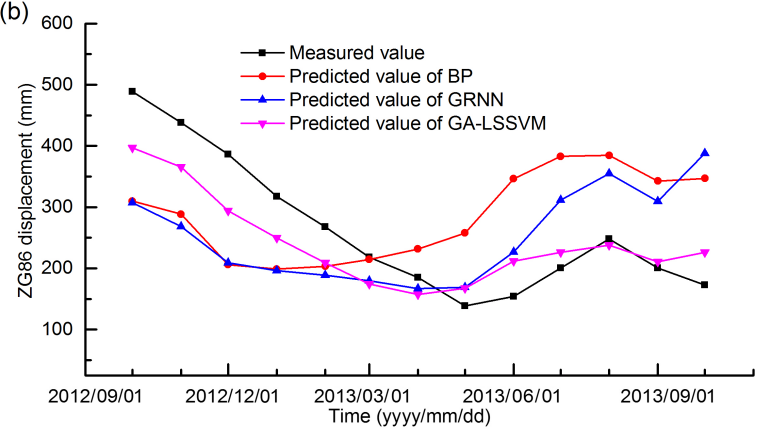

Figure 12. Measured displacement and predicted periodic displacement of Shuping landslide.
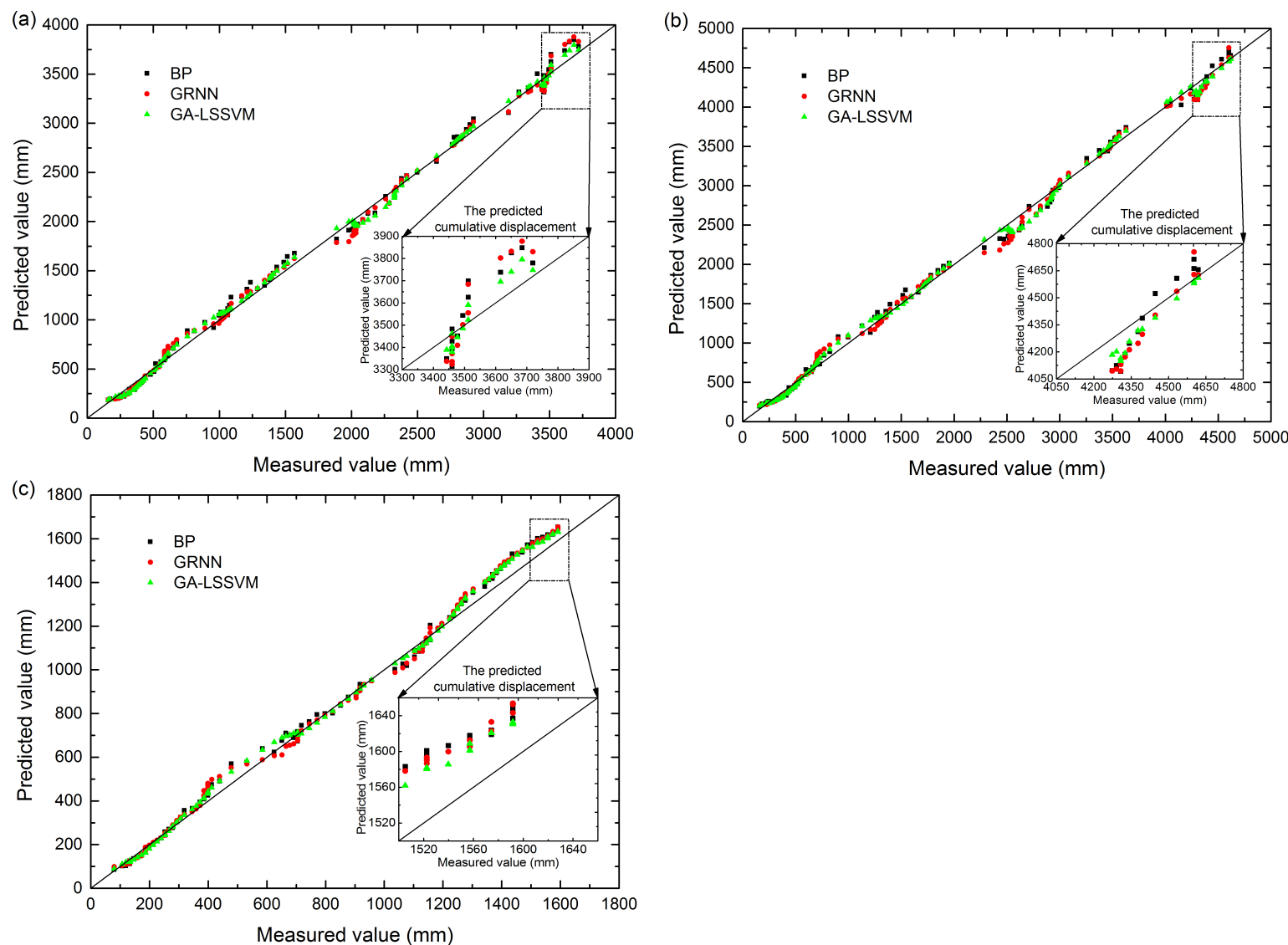

Figure 13. Measured values versus predicted values of the cumulative displacement: (a) monitoring station ZG85, (b) monitoring station ZG86 and (c) monitoring station ZG87. 
Table 6. Comparison of the performance of cumulative displacement prediction for the three models.

\begin{tabular}{l|rrr|rrr|rrr}
\hline \multirow{2}{*}{ Model } & \multicolumn{3}{|c|}{ RMSE (mm) } & \multicolumn{3}{c|}{ MAE (mm) } & \multicolumn{3}{c}{ MAPE (\%) } \\
\cline { 2 - 10 } & ZG85 & ZG86 & ZG87 & ZG85 & ZG86 & ZG87 & ZG85 & ZG86 & ZG87 \\
\hline GA-LSSVM & 62.4146 & 87.7215 & 49.0485 & 53.0048 & 74.0601 & 48.5392 & 1.492 & 1.703 & 3.131 \\
GRNN & 125.8222 & 134.6764 & 59.8173 & 109.6146 & 115.1067 & 59.2756 & 3.079 & 2.643 & 3.821 \\
BP & 111.7842 & 123.1948 & 62.0223 & 96.5585 & 107.6724 & 60.9701 & 2.717 & 2.464 & 3.935 \\
\hline
\end{tabular}

model. The RMSE, MAE and MAPE formulas are as follows:

$$
\begin{aligned}
& \text { RMSE }=\sqrt{\frac{1}{n} \sum_{i=1}^{n}\left(s_{i}-s_{i}^{*}\right)^{2},} \\
& \text { MAE }=\frac{1}{n} \sum_{i=1}^{n}\left|s_{i}-s_{i}^{*}\right|, \\
& \text { MAPE }=\frac{1}{n} \sum_{i=1}^{n}\left|\frac{s_{i}-s_{i}^{*}}{s_{i}},\right|,
\end{aligned}
$$

where $s_{i}$ is the measured value, $s_{i}^{*}$ is the predicted value and $n$ is the number of predicted values.

The performances of different models for landslide displacement prediction are assessed based on the RMSE, MAE and MAPE, as presented in Table 6. The prediction precision of the GA-LSSVM model based on time series analysis is better than that of the GRNN and the BP. Notably, the RMSE, MAE and MAPE values of the GA-LSSVM model were $63.4076,56.6098$ and $1.587 \%$ lower than those of the GRNN model, respectively, and 49.3696, 43.5537 and $1.225 \%$ lower than those of the BP model for monitoring station ZG85. The predicted results for monitoring stations ZG86 and ZG87 exhibited similar trends. According to the prediction results, the GA-LSSVM model has good deduction ability for landslide displacement prediction and can provide assistance in early risk assessment and landslide forecasting.

\section{Conclusion}

Landslide displacement prediction is a major focus of contemporary landslide research. We use the deformation of a episodic movement landslide (Shuping landslide) as an example. According to time series analysis, the cumulative displacement is decomposed into a trend component displacement representing the trend of landslide deformation in the long-term and a periodic component displacement that represents short-term deformation fluctuations. The trend displacement and periodic displacement are predicted using a polynomial function and the GA-LSSVM model, respectively. The LSSVM yields good fitting results in predicting the periodic displacement with the GA, which is utilized to determine the optimal parameters of the LSSVM. Based on our analysis of the deformation of Shuping landslide, the reservoir water level, rainfall and groundwater have major influences on the cumulative displacement. Therefore, based on the relational grades, we select six influential factors as the input variables. The predicted cumulative displacement is obtained from the sum of the predicted trend displacement and the predicted periodic displacement.

The GA-LSSVM model displays the highest accuracy, the smallest RMSE of $62.4146 \mathrm{~mm}$, the smallest MAE of $53.0048 \mathrm{~mm}$ and the smallest MAPE of $1.492 \%$ at monitoring station ZG85, while these three values are $87.7215 \mathrm{~mm}$, $74.0601 \mathrm{~mm}$ and $1.703 \%$ at monitoring station ZG86 and $49.0485 \mathrm{~mm}, 48.5392 \mathrm{~mm}$ and $3.131 \%$ at monitoring station ZG87. The study results show that GA-LSSVM provides good performance for landslide displacement prediction, and the GA is appropriate for determining the optimal parameters used in the LSSVM model. Thus, the GA-LSSVM model can be effectively used to predict landslide displacement and reflect the corresponding relationships between the major influencing factors and the periodic component displacement.

Data availability. The data is available at: https://doi.org/10.13140/RG.2.2.27329.04964.

Competing interests. The authors declare that they have no conflict of interest.

Acknowledgements. The authors would like to gratefully acknowledge the editor and the anonymous reviewers for their constructive criticism on an earlier version of this paper and offering valuable suggestions that contributed to its improvement. This study was supported by National Natural Science Foundation of China, Key Project of National Science Foundation of China (nos. 41230637 and 41502290), the Ministry of Science and Technology of P.R. China, National Basic Research Program of China (973 Program) (2011CB710600). This study was also supported by the National Natural Science Foundation of China (41702328), Fundamental Research Funds for the Central Universities, China University of Geosciences (Wuhan) (CUGL170813).

Edited by: Thomas Glade

Reviewed by: two anonymous referees 


\section{References}

Abdi, M. J. and Giveki, D.: Automatic detection of erythematosquamous diseases using PSO-SVM based on association rules, Eng. Appl. Artif. Intel., 26, 603-608, https://doi.org/10.1016/j.engappai.2012.01.017, 2013.

Ahmed, B.: Landslide susceptibility mapping using multicriteria evaluation techniques in Chittagong Metropolitan Area, Bangladesh, Landslides, 6, 1077-1095, https://doi.org/10.1007/s10346-014-0521-x, 2013.

Ahmadi, M. A., Zendehboudi, S., Lohi, A., Elkamel, A., and Chatzis, I.: Reservoir permeability prediction by neural networks combined with hybrid genetic algorithm and particle swarm optimization, Geophys. Prosp., 61, 582-598, https://doi.org/10.1111/j.1365-2478.2012.01080.x, 2013.

Altınel, B., Can Ganiz, M., and Diri, B.: A corpus-based semantic kernel for text classification by using meaning values of terms, Eng. Appl. Artif. Intel., 43, 54-66, https://doi.org/10.1016/j.engappai.2015.03.015, 2015.

Brockwell, P. J. and Davis, R. A.: Time series: theory and methods, Springer Science \& Business Media, 340-341, 2013.

Cai, Z., Xu, W., Meng, Y., Shi C., and Wang R.: Prediction of landslide displacement based on GA-LSSVM with multiple factors, Bull. Eng. Geol. Environ., 75, 637-646, https://doi.org/10.1007/s10064-015-0804-z, 2016.

Cao, Y., Yin, K., Alexander, D. E., and Zhou, C.: Using an extreme learning machine to predict the displacement of step-like landslides in relation to controlling factors, Landslides, 4, 725-736, https://doi.org/10.1007/s10346-015-0596-z, 2016.

Corominas, J., Moya, J. E., Ledesma, A., Lloret, A., and Gili, J. A.: Prediction of ground displacements and velocities from groundwater level changes at the Vallcebre landslide (Eastern Pyrenees, Spain, Landslides, 2, 83-96, https://doi.org/10.1007/s10346005-0049-1, 2005.

Desai, C. S., Samtani, N. C., and Vulliet, L.: Constitutive modeling and analysis of creeping slopes, J. Geotech. Eng. Trans. ASCE, 121, 43-56, https://doi.org/10.1061/(ASCE)07339410(1995)121:1(43), 1995.

Du, J., Yin, K., and Lacasse, S.: Displacement prediction in colluvial landslides, Three Gorges Reservoir, China, Landslides, 10, 203-218, https://doi.org/10.1007/s10346-012-0326-8, 2013.

Duan, K., Keerthi, S. S., and Poo, A. N.: Evaluation of simple performance measures for tuning SVM hyperparameters, Neurocomputing, 51, 41-59, https://doi.org/10.1016/S09252312(02)00601-X, 2003.

Elbisy, M. S.: Sea wave parameters prediction by support vector machine using a genetic algorithm, J. Coast. Res., 314, 892-899, https://doi.org/10.2112/JCOASTRES-D-13-00087.1, 2015.

Farzan, A., Mashohor, S., Ramli, A. R., and Mahmud, R.: Boosting diagnosis accuracy of Alzheimer's disease using high dimensional recognition of longitudinal brain atrophy patterns, Behav. Brain Res., 290, 124-130, https://doi.org/10.1016/j.bbr.2015.04.010, 2015.

Fei, S., Wang, M., Miao, Y., Tu, J., and Liu, C.: Particle swarm optimization-based support vector machine for forecasting dissolved gases content in power transformer oil, Energ. Convers. Manage., 50, 1604-1609, https://doi.org/10.1016/j.enconman.2009.02.004, 2009.

Feng, X., Zhao, H., and Li, S.: Modeling non-linear displacement time series of geo-materials using evolutionary support vector machines, Int. J. Rock. Mech. Min., 41, 1087-1107, https://doi.org/10.1016/j.ijrmms.2004.04.003, 2004.

Garg, A. and Tai, K.: A hybrid genetic programming-artificial neural network approach for modeling of vibratory finishing process, International Proceedings of Computer Science and Information Technology (IPCSIT), 14-19, 2011.

Garg, A. and Tai, K.: Stepwise approach for the evolution of generalized genetic programming model in prediction of surface finish of the turning process, Adv. Eng. Softw., 78, 16-27, https://doi.org/10.1016/j.advengsoft.2017.01.005, 2014.

Gelisli, K., Kaya, T., and Babacan, A. E.: Assessing the factor of safety using an artificial neural network: case studies on landslides in Giresun, Turkey, Environ. Earth Sci., 73, 8639-8646, https://doi.org/10.1007/s12665-015-4027-1, 2015.

Goetz, J. N., Brenning, A., Petschko, H., and Leopold, P.: Evaluating machine learning and statistical prediction techniques for landslide susceptibility modeling, Comput. Geosci.-UK, 81, 111, https://doi.org/10.1016/j.cageo.2015.04.007, 2015.

$\mathrm{Gu}$, J., Zhu, M., and Jiang, L.: Housing price forecasting based on genetic algorithm and support vector machine, Expert. Syst. Appl., 38, 3383-3386, https://doi.org/10.1016/j.eswa.2010.08.123, 2011.

Guzzetti, F., Reichenbach, P., Cardinali, M., Galli, M., and Ardizzone, F.: Probabilistic landslide hazard assessment at the basin scale, Geomorphology, 72, 272-299, https://doi.org/10.1016/j.geomorph.2005.06.002, 2005.

Hejazi, F., Toloue, I., Jaafar, M. S., and Noorzaei, J.: Optimization of earthquake energy dissipation system by genetic algorithm, Comput-Aided. Civ. Inf., 28, 796-810, https://doi.org/10.1111/mice.12047, 2013.

Hong, H., Pradhan, B., Jebur, M. N., Bui, D. T., Xu, C., and Akgun, A.: Spatial prediction of landslide hazard at the Luxi area (China) using support vector machines, Environ. Earth Sci., 75, p. 40, https://doi.org/10.1007/s12665-015-4866-9, 2016.

Hwang, S., Jeong, M. K., and Yum, B.: Robust relevance vector machine with variational inference for improving virtual metrology accuracy, IEEE T. Semiconduct. M., 27, 83-94, https://doi.org/10.1109/TSM.2013.2286498, 2014.

Kavzoglu, T., Kutlug Sahin, E., and Colkesen, I.: An assessment of multivariate and bivariate approaches in landslide susceptibility mapping: a case study of Duzkoy district, Nat. Hazards, 76, 471496, https://doi.org/10.1007/s11069-014-1506-8, 2015.

Kawabata, D. and Bandibas, J.: Landslide susceptibility mapping using geological data, a DEM from ASTER images and an artificial neural network (ANN), Geomorphology, 113, 97-109, https://doi.org/10.1016/j.geomorph.2009.06.006, 2009.

Kirschbaum, D. B., Adler, R., Hong, Y., Hill, S., and LernerLam, A.: A global landslide catalog for hazard applications: method, results, and limitations, Nat. Hazards, 3, 561-575, https://doi.org/10.1007/s11069-009-9401-4, 2010.

Koza, J. R.: Genetic programming: on the programming of computers by means of natural selection, MIT press, Cambridge, MA, 1-840, 1992.

Lessmann, S., Stahlbock, R., and Crone, S. F.: Optimizing hyperparameters of support vector machines by genetic algorithms, Las Vegas, CSREA Press, 1-7, 2005.

Levasseur, S., Malécot, Y., Boulon, M., and Flavigny, E.: Soil parameter identification using a genetic algorithm, Int. J. Numer. Anal. Met., 32, 189-213, https://doi.org/10.1002/nag.614, 2008. 
Li, F., Tang, B. P., and Liu, W. Y.: Fault diagnosis based on least square support vector machine optimized by genetic algorithm, Journal of Chongqing University, 33, 14-20, 2010.

Lian, C., Zeng, Z. G., Yao, W., and Tang, H. M.: Displacement prediction model of landslide based on a modified ensemble empirical mode decomposition and extreme learning machine, Nat. Hazards, 66, 759-771, https://doi.org/10.1007/s11069-0120517-6, 2013.

Lian, C., Zeng, Z. G., Yao, W., and Tang, H. M.: Ensemble of extreme learning machine for landslide displacement prediction based on time series analysis, Neural Comput. Appl., 24, 99-107, https://doi.org/10.1007/s00521-013-1446-3, 2014.

Lian, C., Zeng, Z., Yao, W., and Tang, H.: Multiple neural networks switched prediction for landslide displacement, Eng. Geol., 186, 91-99, https://doi.org/10.1016/j.enggeo.2014.11.014, 2015.

Lin, P. T.: Support vector regression: Systematic design and performance analysis, Department of Electronic Engineering, National Taiwan University, 1-6, 2001.

Liu, Z., Shao, J., Xu, W., Chen, H., and Shi, C.: Comparison on landslide nonlinear displacement analysis and prediction with computational intelligence approaches, Landslides, 11, 889-896, https://doi.org/10.1007/s10346-013-0443-z, 2014.

Lv, Y., Liu, J., Yang, T., and Zeng, D.: A novel least squares support vector machine ensemble model for NOx emission prediction of a coal-fired boiler, Energy, 55, 319-329, https://doi.org/10.1016/j.energy.2013.02.062, 2013.

Marjanović, M., Kovačević, M., Bajat, B., and Voženílek, V.: Landslide susceptibility assessment using SVM machine learning algorithm, Eng. Geol., 123, 225-234, https://doi.org/10.1016/j.enggeo.2011.09.006, 2011.

Micheletti, N., Foresti, L., Kanevski, M., Pedrazzini, A., and Jaboyedoff, M.: Landslide susceptibility mapping using adaptive support vector machines and feature selection, Geophys. Res. Abstr., EGU, 13, p. 1, 2011.

Min, J. H. and Lee, Y.: Bankruptcy prediction using support vector machine with optimal choice of kernel function parameters, Expert. Syst. Appl., 28, 603-614, https://doi.org/10.1016/j.eswa.2004.12.008, 2005.

Miyagi, T., Yamashina, S., Esaka, F., and Abe, S.: Massive landslide triggered by 2008 Iwate-Miyagi inland earthquake in the Aratozawa Dam area, Tohoku, Japan, Landslides, 1, 99-108, https://doi.org/10.1007/s10346-010-0226-8, 2011.

Nefeslioglu, H. A., Gokceoglu, C., and Sonmez, H.: An assessment on the use of logistic regression and artificial neural networks with different sampling strategies for the preparation of landslide susceptibility maps, Eng. Geol., 97, 171-191, https://doi.org/10.1016/j.enggeo.2008.01.004, 2008.

Pourbasheer, E., Riahi, S., Ganjali, M. R., and Norouzi, P.: Application of genetic algorithm-support vector machine (GA-SVM) for prediction of BK-channels activity, Eur. J. Med. Chem., 44, 5023-5028, https://doi.org/10.1016/j.ejmech.2009.09.006, 2009.

Pradhan, B., Abokharima, M. H., Jebur, M. N., and Tehrany, M. S.: Land subsidence susceptibility mapping at Kinta Valley (Malaysia) using the evidential belief function model in GIS, Nat. Hazards, 73, 1019-1042, https://doi.org/10.1007/s11069014-1128-1, 2014.

Ren, F., Wu, X., Zhang, K., and Niu, R.: Application of wavelet analysis and a particle swarm-optimized support vector machine to predict the displacement of the Shuping landslide in the Three Gorges, China, Environ. Earth Sci., 73, 4791-4804, https://doi.org/10.1007/s12665-014-3764-x, 2015.

Sassa, K., Picarelli, L., and Yin, Y. P.: Monitoring, prediction and early warning, in: Landslides-disaster risk reduction, edited by: Sassa, K. and Canuti, P., Springer-Verlag, Berlin Heidelberg, 351-375, 2009.

Shen, J., Karakus, M., and Xu, C.: Direct expressions for linearization of shear strength envelopes given by the Generalized HoekBrown criterion using genetic programming, Comput. Geotech., 44, 139-146, https://doi.org/10.1016/j.compgeo.2012.04.008, 2012.

Sun, Z., Choi, T., Au, K., and Yu, Y.: Sales forecasting using extreme learning machine with applications in fashion retailing, Decis. Support Syst., 46, 411-419, https://doi.org/10.1016/j.dss.2008.07.009, 2008.

Suykens, J. A. K. and Vandewalle, J.: Least Squares Support Vector Machine Classifiers, Neural Process. Lett., 9, 293-300, https://doi.org/10.1023/A:1018628609742, 1999.

Suykens, J. A. K., De Brabanter, J., Lukas, L., and Vandewalle, J.: Weighted least squares support vector machines: robustness and sparse approximation, Neurocomputing, 48, 85-105, https://doi.org/10.1016/S0925-2312(01)00644-0, 2002.

Tosun, N.: Determination of optimum parameters for multiperformance characteristics in drilling by using grey relational analysis, Int. J. Adv. Manuf. Technol., 28, 450-455, https://doi.org/10.1007/s00170-004-2386-y, 2006.

Turner, D., Lucieer, A., and de Jong, S.: Time series analysis of landslide dynamics using an unmanned aerial vehicle (UAV), Remote Sens.-Basel, 7, 1736-1757, https://doi.org/10.3390/rs70201736, 2015.

Vandenbergh, F. and Engelbrecht, A. P.: A study of particle swarm optimization particle trajectories, Inform. Sci., 176, 937-971, https://doi.org/10.1016/j.ins.2005.02.003, 2006.

Vapnik, V.: The nature of statistical learning theory, Springer Verlag, New York, 1-201, 1995.

Wang, J. F.: Quantitative prediction of landslide using S-curve, Chin J Geol Hazard Control, 14, 3-10, 2003.

Wang, Y., Yin, K. L., and An, G. F.: Grey correlation analysis of sensitive factors of landslide, Rock Soil Mech., 25, 91-93, 2004.

Wen, T., Tang, H., Wang, Y., Lin, C., and Xiong, C.: Shuping landslide-Rainfall and Reservoir water level, https://doi.org/10.13140/RG.2.2.27329.04964, 2017.

$\mathrm{Xu}, \mathrm{H}$. and Chen, G.: An intelligent fault identification method of rolling bearings based on LSSVM optimized by improved PSO, Mech. Syst. Signal Pr., 35, 167-175, https://doi.org/10.1016/j.ymssp.2012.09.005, 2013.

Yao, W., Zeng, Z. G., Lian, C., and Tang, H. M.: Ensembles of echo state networks for time series prediction. In: Sixth international conference on advanced computational intelligence, Hangzhou, China, 299-304, 2013.

Yin, $\mathrm{X}$. and $\mathrm{Yu}, \mathrm{W}$. : The virtual manufacturing model of the worsted yarn based on artificial neural networks and grey theory, Appl. Math. Comput., 185, 322-332, https://doi.org/10.1016/j.amc.2006.06.117, 2007.

Zhang, H., Luo, Y. Y., Zhang, L. T., and Chen, Z.: Cultivated land change forecast based on genetic algorithm and least squares support vector machines, Transactions of the CSAE, 25, 226-231, 2009. 
Zhang, W., Niu, P., Li, G., and Li, P.: Forecasting of turbine heat rate with online least squares support vector machine based on gravitational search algorithm, Knowl.-Based Syst., 39, 34-44, https://doi.org/10.1016/j.knosys.2012.10.004, 2013. 